\title{
Trust and adaptive learning in implicit contracts
}

\author{
Christian Lukas • Jens Robert Schöndube
}

\begin{abstract}
Trust is a phenomenon that still is quite rarely investigated in agency theory. According to a common intuitive reasoning, trust should develop over time and it should evolve even in finite implicit-contract relationships. However, if the contracting parties are fully rational, theory cannot explain this. We therefore extend the standard model and develop a model of a finite relationship where the principal promises to pay a voluntary period-by-period bonus if the agent has worked according to the implicit agreement. The agent is boundedly rational and unable to foresee the principal's future bonus decisions. The principal is, with some probability, honest and pays a promised bonus even in situations where ex-post cheating would be optimal. Based on the agent's adaptive learning process, we show how trust evolves depending on the principal's bonus-payment strategy. Depending on different levels of the agent's bounded rationality, we derive the principal's optimal pure strategy as part of a unique equilibrium. In an extension we show that the results are robust if the agent has bounded recall. The optimal strategy pattern mirrors a subset of trigger strategies which is exogenous in the standard model. Our findings imply that subjective incentives are more effective with increasing tenure of employees, or, that the optimal level of trust depends on how fast work environments change.
\end{abstract}

Keywords Trust - Evolution of trust - Implicit contracts - Bounded rationality . Adaptive learning · Trigger strategies

C. Lukas $(\bowtie)$

University of Konstanz, Universitaetsstrasse 10, Fach D 144,

78457 Konstanz, Germany

e-mail: Christian.Lukas@uni-konstanz.de

J. R. Schöndube

Eberhard Karls University Tuebingen, Nauklerstrasse 47,

72074 Tuebingen, Germany

e-mail: jensrobert.schoendube@uni-tuebingen.de 
JEL Classification D8 - D81 - M12 - M52

\section{Introduction}

Over the past decade, the issue of trust in business transactions has gained increasing attention by researchers. ' It is widely undisputed that trust affects many transactions and increases their value added. Relational contracts often rely on trust. In a knowledge based economy, services delivered to or received from trade partners often require "innovation and knowledge inputs" which render complete contracts prohibitive if not infeasible, and trust - in receiving high quality inputsthen performs much better as a "contract" device than explicit and verifiable contract terms. Besides this interorganizational trust, intra-organizational or interpersonal trust is important, too. Firms, when contracting with their employees, often find it convenient to describe the job requirements in vague terms or they expect employees to provide additional input beyond contracted levels if that is necessary. Employees, in turn, expect firms to reward them for their flexibility and additional performance. As such both parties, employer and employee, expect the other party to behave cooperatively in the absence of binding agreements.

The problem to verify performance (and sign binding contracts) often shows up in incentive contracting with employees. The assumption of verifiable performance used to be standard but as Prendergast (1999, p. 57) notes, "most people don't work in jobs like these". Subjective-non-verifiable-performance evaluation then represents the method of choice. We analyze relational contracts in employee compensation: Responsibilities and tasks of employees are often very complex and ambiguous so that it is impossible to specify explicit performance goals for them. ${ }^{2}$ An important application of relational contracts is strategic performance measurement. It is well documented that aligning employee incentives with firm strategy requires employee compensation being related to financial and non-financial measures. ${ }^{3}$ As non-financial measures are often non-verifiable, Kaplan and Norton (1996) propose subjective rewards. Murphy and Oyer (2003) analyze the use of discretionary bonuses in incentive contracts. They show analytically and confirm empirically that discretionary bonuses are less pronounced for the CEO than for employees (lower-level managers): While the board of directors often does not have enough information for a subjective performance evaluation of the CEO, the CEO, in contrast, can monitor employees on the job and therefore is able to make precise subjective assessments.

To make subjective performance evaluation schemes and processes work it is essential that those who are being evaluated and receive compensation contingent on evaluation trust the process (Baker 1990, p. 55). In the same vein, Ittner and

\footnotetext{
1 Various journals published special issues on "trust", e.g. Academy of Management Review (1998), Journal of Economic Behavior and Organization (2004), or Organization Science (2003).

2 See also Kidder and Buchholtz (2002) with a special focus on executive compensation. They argue that a violation of a relational contract, i.e., trust abusing behavior, reduces executives' stewardship incentives.

${ }^{3}$ See Kaplan and Norton $(1996,2001)$ with reference to the balanced scorecard concept.
} 
Larcker (2003) and Milkovich and Newman (2002, p. 302) argue that transparent and fair performance reviews are crucial to implement efficient variable pay systems. Higher trust of employees in their supervisors and the performance appraisal system helps to increase employee commitment to the company which in turn leads to higher performance. As such trust, incentives and performance interact. The objective of this paper is to analytically explore the interaction.

So far, analytical research on subjective performance evaluation has focused on self-enforcing contracts. Employers were assumed to comply with the implicit part of the contract, i.e., the bonus payment based on subjective performance evaluation, as long as it is beneficial with regard to future payoffs (e.g., Baker et al. 1994; Bull 1987; Levin 2003). ${ }^{4}$

When non-compliance was observed once, the agency could generate only the worst possible surplus in all future periods. This grim trigger strategy was therefore exogenous to the models. Also, trust could not play a role as contracting parties were completely rational and therefore able to foresee bonus payments. In this paper, we extend the aforementioned models and include trust as an integral part of the agency.

In the standard model of implicit contracting where rational parties mutually anticipate their equilibrium strategies, "trust" usually does not evolve over time. ${ }^{5}$ In a dynamic relationship, however, trust should evolve depending on past decisions. ${ }^{6}$ We develop a model where the agent uses the number of previous bonus payments by the principal to update beliefs on the probability that the bonus will be paid in the next period. To establish a model where an evolution of trust is consistent with equilibrium behavior, we use a bounded rationality approach. We assume that there are strategic and non-strategic principals in the market: non-strategic ones who always pay the bonus, and strategic ones who only pay the bonus if it is optimal with regard to future payoffs. The agent does not know whether his employer is a strategic or a non-strategic principal. We assume that he is not able to determine sequential equilibria of the complete equilibrium path and to draw consistent probability assessments therefrom. ${ }^{7}$ Hence the agent's subjective probability assessment for bonus payment in a given period depends only on the observation of previous bonus payments. ${ }^{8}$ The probability increases in the number of payments and decreases in the number of non-payments, i.e., when the principal does not pay the bonus. Trust, measured by the agent's expectation that the bonus will be paid in

\footnotetext{
${ }^{4}$ An alternative way to make subjective bonus payments credible are bonus pools. See Baiman and Rajan (1995) or Rajan and Reichelstein (2009).

MacLeod (2003) analyzes problems that arise when different perceptions between the organization (principal) and the employee (agent) are present, whereas Mitusch (2006) deals with the principal's ability to produce "hard facts", i.e., verifiable performance measures.

${ }^{5}$ In models with pure strategies, "trust" is either perfect, or there is no trust at all.

${ }^{6}$ See also Gürtler (2006).

${ }^{7}$ Camerer and Weigelt (1988, p. 2) suggest it is plausible to assume principals (firms) are able to compute these sequential equilibria, possibly by the help of consultants, but agents (employees) are less likely to calculate them.

${ }^{8}$ Psychological research suggests that if one is unable to calculate exact probabilities and strategies, observed behavior is often the best predictor. (See March (1994, p. 13)).
} 
the next period, crucially determines the cost of inducing a given effort level. The core of the paper is that the history of play is the single source of information the agent uses to determine the principal's trustworthiness.

Trust in agency theory constitutes a less well-developed literature compared to other issues in the study of incentives. Rosen (1992, p. 187) links trust to agency and Jones and George (1998) consider trust as a solution to agency problems. Casadesus-Masanell (2004) formally models trust in a one-period agency. $\mathrm{He}$ defines trust as behavior in rational equilibrium strategies. ${ }^{9}$ Our definition of trust differs: If a person trusts institutions or persons (so called behavioral trust), she/he accepts that they may take advantage of her/him though she/he expects them not to do so. ${ }^{10}$ Based on the assumption of good (or bad) intentions one could reasonably impute trusted institutions or persons to play pure strategies. We show that an essential feature of a trust relationship - the gradual building and dissipation of trust - would not obtain in our model if we assumed full rationality (even if paired with incomplete information). Therefore, a departure from the full rationality assumption is necessary.

Related to our paper is the literature on reputation in repeated games (Kreps and Wilson 1982; Mailath and Morris 2002; Mailath and Samuelson 2006), specifically non-zero-sum games with incomplete information (Aumann and Maschler 1995; Forges 1992). Solutions to these games usually constitute a set of a possibly large number of equilibria and there is no reliable prediction which will prevail. ${ }^{11}$ Put differently, various trigger strategies can sustain an equilibrium (Friedman 1971). To single out an equilibrium, an assumption concerning a particular punishment has to be made (e.g., Green and Porter 1984), or a certain level of "irrationality" is needed (Fudenberg and Maskin 1986). While the cited work considers simultaneous moves by players, our model is based on sequential play. It is therefore most closely (although not closely) related to reputation models in financial contracting (e.g. Boot et al. 1993; John and Nachman 1985). Boot et al. (1993) analyze reputation formation with fully rational agents in a three-period model. A separating or a pooling equilibrium may obtain. In our model, a pooling equilibrium in a $T$-period relationship obtains because agents are boundedly rational. Therefore our results relate to employer-employee relations but the analysis in Boot et al. (1993) probably better predicts outcomes for games played between firms.

Our paper is also related to recent contributions on reputation in long-term relationships where the nature of a party may change over time, e.g., where corporate culture changes with the appointment of a new board of directors. If say, trustworthy and non-trustworthy organizations are in the market and organizations possess superior information compared to employees or suppliers, Cripps et al. (2004) show that it is impossible for non-trustworthy organizations to maintain a long-term reputation for being trustworthy if the latter behavior does not represent an equilibrium in this situation. Therefore, reputation becomes valuable (again) only if organizations (and their culture) may change over time. Phelan (2006) and Wiseman (2008) consider repeated interactions in such long-term relationships.

\footnotetext{
${ }^{9}$ See also Casadesus-Masanell and Spulber (2007).

${ }^{10}$ This is a very common definition of trust. See, Nooteboom (2006, p. 249).

${ }^{11}$ See also Kreps (1990, p. 102f).
} 
Both find that non-trustworthy organizations optimally switch back and forth between investing in reputation (behaving trustworthy) and exploiting reputation (betraying trust). In our analysis we prove that switching back and forth between investing in and exploiting reputation does not represent optimal behavior for an organization that acts strategically. The result requires full recall by agents. If agents are characterized by bounded recall, a strategic organization (principal) exploits the agent's forgetfulness by switching back and forth with her decisions over the total course of time. However, within a time span that is recalled by the agent, the optimal strategic behavior is structurally equivalent to the perfect recall case.

The contribution of our paper is twofold. First, we include trust and - associated with it - (slightly and reasonably) bounded rationality of agents in implicit contracts. In this way, we extend the standard implicit contract model by the evolution of trust through adaptive learning by the agent. Several important results emerge from this analysis, and since they do not depend qualitatively on the ex ante "distribution" of trust, they are generalizable in the sense that circumstances with quite different levels of ex ante trust lead to the same strategy patterns being optimal. For a sufficiently low interest rate the principal will pay the voluntary bonus - if at all - at the beginning of an agency and not pay the bonus towards the end. This outcome mirrors the grim trigger strategy which is usually exogenously entered into implicit contracting models to sustain an equilibrium. Our paper can therefore provide a rationale and some justification for the popular use of that approach. The equivalence is shown by assuming full memory of the agent in our trust setting. With bounded recall the principal switches back and forth between bonus payment and non-payment. However, in a representative decision sequence that depends on the number of periods the agent recalls the optimal strategy pattern is equivalent to perfect recall: the principal establishes trust by subsequent bonus payments and harvests it by subsequent non-payments. Depending on how many periods the agent recalls, we endogenously derive strategy profiles that mirror different trigger strategies that are also exogenous to previous models. An optimal and a critical (or minimal) level of trust in the agency will be identified as well.

Second, our results contribute to game theory by deriving pure strategy profiles as unique incomplete-information equilibria in dynamic two-player sequential move games. The specific equilibrium depends on how boundedly rational the agent is, i.e., whether he is able to recall the entire history of play or only a limited number of periods.

Finally, our research has implications for performance evaluation practices which we discuss in detail.

From here on we proceed as follows. The next section introduces the model and the following section analyzes optimal strategies and the evolution of trust. It includes a discussion of the benchmark case of full rationality. An extension of the model, bounded recall by the agent, is presented in Sect. 4. In Sect. 5 we interpret and apply our findings. The final section concludes.

\section{The model}

We consider a long-term agency relationship of $T$ periods with spot (one period) contracts. The agent's action in period $t$ is $e_{t} \in[0,1]$, at cost $c\left(e_{t}\right)=e_{t}^{2} / 2$. Actions 
are observable but not verifiable. The principal's expected gross outcome (before compensation) in period $t$ is $e_{t}$; it is not contractible.

At the end of every period $t, t=1,2, \ldots, T$, the agent receives compensation $W_{t}$, consisting of a fixed component $s_{t}$ (which is guaranteed by the contract) and a nonenforceable bonus payment $b_{t}=v_{t} e_{t}$ by the principal. The bonus equals a share of the expected output in period $t$ with sharing rate $v_{t}$. Contingent on observation of $e_{t}$, the principal decides to pay the bonus or not. ${ }^{12} \mathrm{We}$ assume risk neutrality for both parties and the agent's reservation utility is zero in each period.

Trust is modeled as the probability-from the agent's point of view-that the principal will pay the bonus at the end of period $t$; in other words, although the principal may have a short-term incentive to renege on the bonus promise the agent expects the principal not to do so, which is a common definition of trust (Nooteboom 2006, p. 249). We assume that there are two types of equally productive principals in the market: the honest (non-strategic) principal who always pays the bonus and the dishonest (strategic) principal who only pays the bonus if it is optimal with respect to future payoffs. At the beginning of the relationship, the agent "draws" one principal from the pool (and remains with the same principal over the course of the agency). The agent does not know whether he is working for a strategic principal or for a non-strategic one. We assume the agent to be boundedly rational in the sense that he is not able to determine the sequential equilibrium in this dynamic relationship. ${ }^{13}$ Instead, by entering the relationship, the agent has some initial trust. Specifically, the agent knows that he faces a non-strategic principal at the beginning of the first period with probability $E(\gamma)=\frac{\alpha}{\alpha+\beta}, \alpha, \beta>0$. The distribution $g(\gamma)$ is a beta distribution with parameters $\alpha$ and $\beta$, so that initial trust is identified as its mean. To prevent that the agent assigns non-payment of the bonus unambiguously to a strategic principal, the principal may pretend to have been hit by unforeseeable contingencies that do not allow for a bonus payment. The agent cannot verify the occurrence of such contingencies.

Trust evolves via Bayesian updating based on the history of bonus payments. Let $\theta_{t}=0$ indicate non-payment and $\theta_{t}=1$ indicate payment of the voluntary bonus in period $t$. Then, at the beginning of period $t$, the expected probability that the bonus will be paid at the end of period $t$ given a history $\theta^{t-1}=\left(\theta_{1}, \theta_{2}, \ldots, \theta_{t-1}\right)$ is given by $^{14}$

\footnotetext{
12 Formally, the contract of period $t$ can be thought of as consisting of an explicit fixed payment $s_{t}$, an implicit effort level $e_{t}$, and an implicit bonus $b_{t}$. If the agent has performed the pre-specified level of effort in period $t$, he is eligible for bonus payment. Instead of including the desired effort level explicitly into the contract we let the agent's effort being induced via the bonus function $b_{t}=v_{t} e_{t}$, depending on the observed effort level $e_{l}$. As both parties are risk-neutral the principal can induce every desired level $e_{i}$ between 0 and 1 via the bonus function at the same cost as with directly writing this level into the contract. Consequently, there is no loss of generality in using this approach.

13 There are a number of experimental studies showing that individuals fail to correctly apply backward induction (see, e.g., Binmore et al. 2002; or Johnson et al. 2002), or do not plan ahead (Hey and Knoll 2007).

14 Note that, from an agent's point of view, the principal's decision to pay the bonus is a draw from a Bernoulli distribution with $\gamma$ as the unknown parameter. As this parameter has a beta distribution with $(\alpha$, $\beta$ ), the draw can be used to update the agent's probability assessment of $\gamma$ (DeGroot 1970, p. 160).
} 


$$
E\left(\gamma \mid \theta^{t-1}\right)=\frac{\alpha+\sum_{i=1}^{t-1} \theta_{i}}{\alpha+\beta+t-1} .
$$

Equation 1 describes the evolution of trust in our model. Starting from the initial trust assessment characterized by $\alpha, \beta>0$, the agent collects $(t-1)$ observations until period $t$ starts. Every bonus payment by the principal increases trust since $\sum_{i=1}^{t-1} \theta_{i}$ is the number of bonus payments; and every non-payment reduces trust. Thus, updating follows technically Bayes' rule (so beliefs are consistent in that respect) but the updating process is intuitively appealing, too, which it should be in light of the bounded rationality assumption. The agent views every bonus payment as a sign that the principal will behave trustworthy in the future, and every nonpayment as a sign that she will not. In that respect trust evolves according to a simple adaptive learning process.

The trust dynamics assumed by Eq. 1, i.e., the gradual building and dissipation of trust, have been observed in experimental studies (Jonker et al. 2004) and field studies (Butler 1983). Equation 1 captures the history-dependence of trust formation and is therefore in line with the well-known approach of history-based trust. $^{15}$

At this point, a note on the functional assumption of the beta distribution seems appropriate. The beta distribution is rich in the sense that it includes quite different symmetric and non-symmetric forms. Therefore, virtually any ex ante assessment of trust can be mapped. Moreover, the level of trust and its fragility separate: A trust level of, say, 0.9 obtains in case 1 from $\alpha_{1}=9$ and $\beta_{1}=1$, but also from $\alpha_{2}=18$ and $\beta_{2}=2$ in case 2 . In case 1 , trust is more fragile than in case 2 because the initial assessment may rest upon fewer observations or less information. Note also that by the principle of insufficient reason the uniform distribution can represent initial trust in our model as well since it obtains as a special case of the beta distribution with $\alpha=\beta=1$.

Two properties of the beta distribution are crucial for our analysis. First, trust increases in bonus payments, and second, early (non)payments lead to more pronounced changes in the trust level than later (non)payments. Both properties accord with intuition. The latter implies moderate updating after several observations, though, which could be disputed because non-payments should lead to a drastic decrease in trust. Such reasoning is in line with the concept of fragile trust (Boyle and Bonacich 1970; Lewicki and Bunker 1995; or Worchel 1979). Yet in our model the agent cannot verify whether it is the principal's non-payment decision or the occurrence of contingencies that render bonus payments impossible. Hence, trust could well be robust (Luhmann 1979). Another property of the beta distribution - the number but not the pattern of (non)payments determines the trust level-may be seen as restrictive because after $n$-rounds, (i) $n / 2$ payments alternating with $n / 2$ non-payments lead to the same trust level as (ii) $n / 2$ payments at the beginning and $n / 2$ non-payments towards the end. Admittedly, this could have an impact; but we are not aware of compelling empirical evidence concerning path dependent updating and therefore decided to assume path independence in our

\footnotetext{
${ }^{15}$ See Kramer (1999) for further explanations and references for its validity.
} 
analysis. ${ }^{16}$ However, the effect of a recency bias which would lead to a lower trust level in (ii) than in (i) is addressed in Sect. 4.

\section{Optimal strategies and the evolution of trust}

\subsection{Benchmark: full rationality}

Consider our implicit contracting model with a fully rational agent and without unforeseeable contingencies. In this setting if a strategic principal deviates from behaving trustworthy (to pay the bonus in every period) the agent can unambiguously identify her. Ex ante, the agent does not know whether he works for a nonstrategic principal or a strategic principal, but he knows the probability distribution of facing a strategic principal. In such a situation the agent's effort choice in a given period depends on his probability assessment of bonus payment by his principal in this period. If the agent was indeed fully rational, this probability assessment would be endogenous in the sense that it is consistent with the strategic principal's equilibrium strategy - and the agent knows this strategy. If it is optimal on the equilibrium path for the strategic principal to pay the bonus in a given period, the rational agent sets the probability for this period equal to one. In case of a separating-equilibrium strategy combination in a period (that is, the non-strategic principal pay the bonus, the strategic principal does not), the probability assessment for this period equals the prior belief if the strategic principal has not been identified before. If the strategic principal is identified, consistent beliefs set the probability of bonus payment in the future to zero. Note that a trust dynamic as in Eq. 1 cannot obtain because the probability to work for a non-strategic principal remains at its prior until identification of the strategic principal; then this probability jumps to one.

Including the possibility of unforeseen contingencies leads to a game of imperfect monitoring and non-payments do not disclose the principal's type. If purestrategy equilibria could be sustained, the agent would correctly foresee the strategic principal's decisions. If the principal is expected to pay a bonus in a given period, the observation of payment is completely non-informative and the probability to work for a non-strategic principal is equal to its prior. Again no trust solution would obtain.

If the strategic principal plays a mixed strategy, bonus payments become informative so that she has incentives to pay the bonus. As in Phelan (2006) the mixed-strategy equilibrium will show switching back and forth between payment and non-payment. Our following analysis demonstrates that this mixing does not constitute equilibrium behavior under bounded rationality.

\footnotetext{
${ }^{16}$ A more general stochastic structure with the first two properties could be used to arrive at qualitatively identical results. For unbounded recall it would still be analytically traceable but not for the analysis of bounded recall. To obtain closed-form solutions in both cases without changing the stochastic structure we decided in favor of the beta distribution.
} 


\subsection{Bounded rationality}

From now on we assume the agent is unable to determine sequential equilibria of the dynamic relationship with the principal. At the beginning of every contracting period the principal offers a linear contract $W_{t}$. As the agent knows the principal's one shot problems, he is also able to determine the optimal current period contract given the principal is willing to pay the bonus. Denote $b_{t}^{*}$ the optimal bonus for period $t$ for a principal who is willing to pay the bonus, consistent with probability assessment $E\left(\gamma \mid \theta^{t-1}\right)$ by the agent. As periods are independent in terms of stochastic output, the optimal bonus $b_{t}^{*}$ is independent of the length of the relationship. In the next section, we will determine that bonus $b_{t}^{*}$ before we determine optimal payment decisions based on $b_{t}^{*}$ in the multi-period problem in Sect. 3.2.2.

\subsubsection{The single-period problem}

To determine the solution to the principal's multi-period decision problem, we consider first a single arbitrary period $t$ of the relationship between principal and agent with expected probability $E\left(\gamma \mid \theta^{t-1}\right)$ that the bonus will be paid. The corresponding optimization problem is given by:

$$
\begin{gathered}
\max _{s_{t}, v_{t}}\left(e_{t}-v_{t} e_{t}-s_{t}\right) \\
\text { s.t. } \\
s_{t}+E\left(\gamma \mid \theta^{t-1}\right) v_{t} e_{t}-c\left(e_{t}\right) \geq 0 \\
e_{t}=\arg \max _{\widehat{e_{t}}} s_{t}+E\left(\gamma \mid \theta^{t-1}\right) v_{t} \widehat{e_{t}}-c\left(\widehat{e_{t}}\right)
\end{gathered}
$$

The principal maximizes her expected output net of the agent's expected compensation, $E\left(e_{t}-b_{t}-s_{t}\right)=\left(e_{t}-v_{t} e_{t}-s_{t}\right)$, taking into account that the contract must be individually rational (Eq. 3) and incentive compatible (Eq. 4). The agent's objective function is expected compensation, $E\left(s_{t}+b_{t}\right)=s_{t}+E\left(\gamma \mid \theta^{t-1}\right) v_{t} e_{t}$, less cost of effort, $c\left(e_{t}\right)$. Incentive compatibility condition Eq. 4 can also be written as

$$
e_{t}=E\left(\gamma \mid \theta^{t-1}\right) v_{t}
$$

It is obvious that the level of trust impacts the effort choice; higher levels of trust allow to implement higher effort levels for a given bonus rate $v_{t}$.

With a binding participation constraint, $s_{t}^{*}=c\left(e_{t}^{*}\right)-E\left(\gamma \mid \theta^{t-1}\right) v_{t}^{*} e_{t}^{*}$ obtains and the optimal bonus rate $v_{t}^{*}$ and induced action $e_{t}^{*}$ can be derived as

$$
\begin{gathered}
v_{t}^{*}=\frac{c^{\prime}\left(e_{t}^{*}\right)}{E\left(\gamma \mid \theta^{t-1}\right)}=\frac{1}{2-E\left(\gamma \mid \theta^{t-1}\right)}, \\
e_{t}^{*}=\frac{E\left(\gamma \mid \theta^{t-1}\right)}{2-E\left(\gamma \mid \theta^{t-1}\right)} .
\end{gathered}
$$

If trust was perfect, $E\left(\gamma \mid \theta^{t-1}\right)=1$, Eqs. 5 and 6 would lead to $e_{t}^{*}=v_{t}^{*}=b_{t}^{*}=1$, and a benchmark surplus of $S_{t}^{H}=\frac{1}{2}$ when the principal honors $(H)$ the contract. 
With trust being imperfect, $E\left(\gamma \mid \theta^{t-1}\right)<1$, inefficiency results. When the principal pays the bonus, i.e., behaves honestly, her expected surplus as a function of induced trust $E\left(\gamma \mid \theta^{t-1}\right)$ is given by

$$
S_{t}^{H}=e_{t}^{*}-v_{t}^{*} e_{t}^{*}-s_{t}^{*}=\frac{1}{2} \frac{E\left(\gamma \mid \theta^{t-1}\right)}{\left(2-E\left(\gamma \mid \theta^{t-1}\right)\right)}<\frac{1}{2},
$$

while the agent ex ante always receives his reservation utility in equilibrium.

Imperfect trust does not restrict the set of implementable actions. The principal could always set $v_{t}=1 / E\left(\gamma \mid \theta^{t-1}\right)$ to induce first-best incentives. However, implementing the first best action is too costly for the principal if $E\left(\gamma \mid \theta^{t-1}\right)<1$. Similarly to Gürtler (2006), the agent weights his bonus with the probability of a bonus payment $\left(E\left(\gamma \mid \theta^{t-1}\right) v_{t} e_{t}\right)$ but the principal has to bear the full cost of compensation $v_{t} e_{t}$. Hence, the optimal bonus $b_{t}^{*}$ solves a trade-off between incentives and (imperfect) trust: The lower the level of trust the higher the required bonus to induce a given level of effort and - at the same time - the higher the cost of imperfect trust (in terms of expected compensation) resulting from the distortion in the agent's incentives. This cost is given by $v_{t} e_{t}\left(1-E\left(\gamma \mid \theta^{t-1}\right)\right)$. With perfect trust this term vanishes, but with imperfect trust this cost is increasing in the bonus rate $v_{t}$. Inefficiency here results already from limited trust.

If the principal does not pay the bonus, i.e., behaves dishonestly $(D)$, the resulting surplus is

$$
S_{t}^{D}=e_{t}^{*}-s_{t}^{*}=\frac{E\left(\gamma \mid \theta^{t-1}\right)\left(4-E\left(\gamma \mid \theta^{t-1}\right)\right)}{2\left(E\left(\gamma \mid \theta^{t-1}\right)-2\right)^{2}}>S_{t}^{H} .
$$

Hence, in any single period problem, the principal is better-off by not paying the bonus.

\subsubsection{The multi-period problem}

In what follows we analyze a relationship between a strategic principal and an agent. By assumption, a non-strategic principal always pays the bonus unless an unforeseen contingency prevents it. Because of the agent's bounded rationality, i.e., limited foresight, a non-strategic principal cannot credibly disclose that she is a trustworthy employer by acting "strategically" and choosing not to pay the bonus in a period in which a strategic principal pays the bonus. Therefore, the optimal strategy of a strategic principal and the incessant bonus decisions of a non-strategic principal fully describe the equilibrium. That equilibrium reacts to the likelihood of facing a strategic principal (or, equivalently, a non-strategic principal) because the optimal strategy of a strategic principal is contingent on $\gamma$. To sustain our equilibrium we impose the following out-of-equilibrium belief for the agent: If a bonus $b_{t}>b_{t}^{*}$ is offered to the agent he views it as indication for a strategic principal-just as a non-payment is. Hence an offer $b_{t}>b_{t}^{*}$ leads to a no-bonus contract and trust is reduced in the same way as following a non-payment. The nobonus contract leads to the lowest possible expected surplus for the principal 
because the minimum effort is expended. Any bonus offer $b_{t}<b_{t}^{*}$ will be accepted and contingent on the bonus payment trust increases. From a principal's point of view, $b_{t}<b_{t}^{*}$ is suboptimal since higher incentives are credible and increase her expected surplus. Hence, in equilibrium the principal offers a bonus $b_{t}^{*}$ in period $t$.

In the multi-period problem let $\theta^{t-1}=\left\{\theta_{1}, \ldots, \theta_{t-1}\right\}$ be the history of bonus payments up to the beginning of period $t$. Furthermore let $\gamma_{t-1}\left(\theta^{t-1}\right) \equiv E\left[\gamma \mid \theta^{t-1}\right]$ be the expected probability (from the agent's perspective given his adaptive learning process) that the bonus will be paid in period $t$ given history $\theta^{t-1}$. Define $S_{t}\left(\theta^{t-1}\right)$ as the principal's surplus in period $t$ given $\theta^{t-1}$. According to surplus values defined in Eqs. 7 and 8 we have

$$
S_{t}^{H}\left(\theta^{t-1}\right)=\frac{1}{2} \frac{\gamma_{t-1}\left(\theta^{t-1}\right)}{\left(2-\gamma_{t-1}\left(\theta^{t-1}\right)\right)}
$$

and

$$
S_{t}^{D}\left(\theta^{t-1}\right)=\frac{\gamma_{t-1}\left(\theta^{t-1}\right)\left(4-\gamma_{t-1}\left(\theta^{t-1}\right)\right)}{2\left(\gamma_{t-1}\left(\theta^{t-1}\right)-2\right)^{2}} .
$$

Surpluses depend on trust $\gamma_{t-1}$ induced by history $\theta^{t-1}$ at the beginning of the period. A principal's pure strategy $\boldsymbol{\theta}=\left(\theta_{1}, \theta_{2}, \ldots, \theta_{T}\right)$ specifies for each period $t$ a decision $\theta_{t} \in\{0,1\}$. The principal's ex ante expected payoff of period $t$ when playing strategy $\boldsymbol{\theta}$ equals $S_{t}(\boldsymbol{\theta})=S_{t}\left(\theta^{t-1}\right) \in\left\{S_{t}^{H}\left(\theta^{t-1}\right), S_{t}^{D}\left(\theta^{t-1}\right)\right\}$. Each strategy $\boldsymbol{\theta}$ leads to a unique evolution of trust over the duration of the agency such that for a specific strategy, surpluses can be written as a function of trust, $S_{t}^{H}\left(\gamma_{t-1}\right)$ and $S_{t}^{D}\left(\gamma_{t-1}\right)$, suppressing the specific history $\theta^{t-1}$ behind it.

Let $\boldsymbol{\theta}^{*}=\left(\theta_{1}^{*}, \theta_{2}^{*}, \ldots, \theta_{T}^{*}\right)$ denote the principal's optimal strategy, then bonus payment in period $t$ implies

$$
S_{t}^{H}\left(\boldsymbol{\theta}^{*}\right)+\sum_{i=t+1}^{T} \delta^{i-t}\left[S_{i}\left(\boldsymbol{\theta}^{*}\right)\right] \geq S_{t}^{D}\left(\boldsymbol{\theta}^{*}\right)+\sum_{i=t+1}^{T} \delta^{i-t}\left[S_{i}\left(\boldsymbol{\theta}^{* *}\right)\right] \text { for all } \boldsymbol{\theta}^{* *} \neq \boldsymbol{\theta}^{*}
$$

holds, where $\delta^{i}=\frac{1}{(1+r)^{i}}$ is the discount factor with interest rate $r \geq 0$ and $\theta^{* *}=\left(\theta_{1}^{*}, \theta_{2}^{*}, \ldots, \theta_{t-1}^{*}, 0, \ldots, \theta_{T}\right)$ denotes strategies that are equal to $\boldsymbol{\theta}^{*}$ up to period $t-1$, and have non-payment in period $t .{ }^{17}$ Constraint Eq. 11 can be rewritten as:

$$
\sum_{i=t+1}^{T} \delta^{i-t}\left[S_{i}\left(\boldsymbol{\theta}^{*}\right)-S_{i}\left(\boldsymbol{\theta}^{* *}\right)\right] \geq S_{t}^{D}\left(\boldsymbol{\theta}^{*}\right)-S_{t}^{H}\left(\boldsymbol{\theta}^{*}\right) \text { for all } \boldsymbol{\theta}^{* *} \neq \boldsymbol{\theta}^{*}
$$

with $S_{t}^{D}\left(\boldsymbol{\theta}^{*}\right)-S_{t}^{H}\left(\boldsymbol{\theta}^{*}\right)=\frac{\gamma_{t-1}\left(\theta^{* t-1}\right)}{\left(\gamma_{t-1}\left(\theta^{* t-1}\right)-2\right)^{2}}$. The principal pays the bonus in period $t$ only if the opportunity cost from bonus payment, $S_{t}^{D}\left(\boldsymbol{\theta}^{*}\right)-S_{t}^{H}\left(\boldsymbol{\theta}^{*}\right)$, is smaller than the benefit from paying the bonus in terms of the discounted sum of future profit differentials $\sum_{i=t+1}^{T} \delta^{i-t}\left[S_{i}\left(\boldsymbol{\theta}^{*}\right)-S_{i}\left(\boldsymbol{\theta}^{* *}\right)\right]$. Hence, the principal's optimal strategy $\boldsymbol{\theta}^{*}$ is the solution to the following dynamic optimization problem: Beginning with the last period the principal determines in every period $t$ her optimal decision $\theta_{t}^{*}\left(\theta^{t-1}\right)$

\footnotetext{
${ }^{17}$ Notice that by definition $S_{t}^{D}\left(\boldsymbol{\theta}^{* *}\right)=S_{t}^{D}\left(\boldsymbol{\theta}^{*}\right)$.
} 
as a function of the history $\theta^{t-1}$ by maximizing period $t^{\prime} s$ contribution plus optimal contributions of future periods.

Define

$$
\begin{aligned}
\mathcal{S}(\boldsymbol{\theta}) & =\sum_{t=1}^{T}\left[S_{t}(\boldsymbol{\theta})\right] \delta^{t-1} \\
& =\sum_{t=1}^{T} S_{t}^{H}\left(\theta^{t-1}\right) \theta_{t} \delta^{t-1}+\sum_{t=1}^{T} S_{t}^{D}\left(\theta^{t-1}\right)\left(1-\theta_{t}\right) \delta^{t-1}
\end{aligned}
$$

as expected ex ante surplus given strategy $\boldsymbol{\theta}$. Then

$$
\boldsymbol{\theta}^{*} \in \underset{\boldsymbol{\theta}}{\operatorname{argmax}} \mathcal{S}(\boldsymbol{\theta}) \text {. }
$$

Notice that the optimal path of payment or non-payment decisions is not trivial in this model. Although we assume a stationary production process, periods differ in the level of trust and this level determines the cost of inducing a given effort. The principal's optimal strategy solves the following trade-off: If she does not pay bonus today she earns surplus $S^{D}$ instead of $S^{H}$, but she also damages trust such that future payoffs become lower. In addition, with an increasing interest rate the value of future surpluses decreases.

To answer the question whether a higher level of initial trust can compensiate for a higher interest rate, observe that both expected surplus from payment, $S_{t}^{H}$, and from non-payment, $S_{t}^{D}$, increase in the expected value of $\gamma$, i.e., in the level of trust:

$$
\begin{aligned}
& \frac{d S_{t}^{H}\left(\theta^{t-1}\right)}{d \gamma_{t-1}}=\frac{1}{\left(2-\gamma_{t-1}\right)^{2}}>0 \\
& \frac{d S_{t}^{D}\left(\theta^{t-1}\right)}{d \gamma_{t-1}}=\frac{4}{\left(2-\gamma_{t-1}\right)^{3}}>0 .
\end{aligned}
$$

Since Eqs. 14 and 15 are positive in every period given any history of play, a higher ex ante level of trust increases every term included in the sum in Eq. 13 and thus increases the surpluses generated by the employer-employee relationship.

\section{Proposition 1}

(a) $\frac{d \mathcal{S}\left(\theta^{*}\right)}{d r}<0$; the expected equilibrium surplus is decreasing in $r$.

(b) With an increasing interest rate $r, \sum_{i}^{t} \theta_{i}$ weakly decreases; less payments become optimal.

(c) $\frac{d \mathcal{S}\left(\theta^{*}\right)}{d \gamma_{0}}>0$; a higher level of ex ante trust increases the expected equilibrium surplus.

Proof From here on, all proofs are relegated to the appendix.

If it is optimal for the principal to pay the bonus in some period, trust builds up according to the agent's adaptive learning process which generates higher future surpluses. If the interest rate $r$ is increasing, however, the value of future surpluses decreases (part (a)). It follows that building up trust becomes less attractive. Hence, 
the optimal number of payments $\sum_{i}^{t} \theta_{i}$ up to some period $t$ is weakly decreasing in the interest rate $r$ (part (b) of the proposition). This implies that the optimal level of trust built up until the beginning of any period is also decreasing in $r$. One immediate conclusion from this result is that if non-payment in every period is optimal for some interest rate $r$ it must be optimal for all interest rates higher than $r$. Part (c) of proposition 1 accords with intuition as a higher level of trust ceteris paribus increases the expected surplus of the relationship. The higher the initial trust the higher the agent's effort for a given bonus and therefore the lower the cost of motivating a certain effort level. Thus, higher initial trust leads ceteris paribus to higher payoffs in every period and offsets, at least partially, the negative effect of a high interest rate on the viability of trust inducing bonus payments. Notice, however, that part (c) of the proposition does not imply that higher initial trust makes bonus payments more attractive. Here two countervailing effects emerge: On the one hand, a higher $\gamma_{0}$ generates higher surpluses for a given strategy; on the other hand, higher trust offers higher payoffs from non-payments. The optimal strategy trades-off these effects.

Next the pattern of the optimal strategy $\theta^{*}$ will be derived. We need the following definitions for that purpose.

Definition 1 (Strict strategy) A strategy $\theta$ is called strict, if it features the same decision in every period.

Definition 2 (Alternating strategy) A strategy $\theta$ is called alternating, if it features more than one switch between payment and non-payment during the agency.

Definition 3 (Non-alternating strategy) A strategy $\boldsymbol{\theta}$ is called non-alternating, if it features exactly one switch between payment and non-payment during the agency (or vice versa).

Clearly, strict payment cannot be the optimal strategy but it generates higher profits than strict non-payment if the agency lasts long enough. To see this, note that period surpluses from strict non-payment eventually approach zero because trust drops to zero; strict payment generates full trust and period surpluses approach $\frac{1}{2}$. This leads to the following lemma:

Lemma 1 If $r$ is sufficiently low, there exists a threshold value $\widetilde{T}$ of the length of the contracting relationship $T$ such that strict payment dominates strict nonpayment, $\boldsymbol{\theta}=\mathbf{1} \succ \boldsymbol{\theta}=\mathbf{0}$ if $T>\widetilde{T}$.

Lemma 1 proves the profitability of trust investments through bonus payments. To increase profit beyond the level from strict payment, the principal decides on the number and periods of non-payments. An important question is yet unanswered: Should the principal pay the bonus at the beginning or towards the end of the relationship? Higher trust allows to implement higher effort, and it offers the chance to realize higher bonus savings from non-payment. Therefore, the earlier the principal starts with establishing trust by paying the bonus the more periods she can benefit from higher trust levels. However, the early bonus payments come at the cost of postponing bonus savings into the future. Given a sufficiently low interest rate, benefits of early payments should exceed its costs. Proposition 2 confirms the conjecture. 
Proposition 2 If $r$ is sufficiently low, the principal's optimal strategy is nonalternating. Given $\tau$ payments are optimal, $0 \leq \tau<T$, the optimal strategy pattern is $\boldsymbol{\theta}^{*}=\left(\theta_{1}=1, \theta_{2}=1, \ldots, \theta_{\tau}=1, \theta_{\tau+1}=0, \ldots, \theta_{T}=0\right)$ : Bonus payments will be observed - if at all - at the beginning of the relationship (and correspondingly: nonpayments will be observed at the end of the relationship).

Putting lemma 1 and proposition 2 together, either a non-alternating strategy starting with payment or strict non-payment will be observed. Since $S_{\tau}^{D}\left(\theta^{\tau-1}\right)>$ $S_{\tau}^{H}\left(\theta^{\tau-1}\right)$ holds in any period $\tau$ given any history $\theta^{\tau-1}$, the strategy "strict payment" over a length of $T$ periods is dominated by the strategy $\left(\theta_{1}=1, \theta\right.$ $2=1, \ldots, \theta_{T-1}=1, \theta_{T}=0$ ). (The latter simply means that the principal reneges on the bonus promise in the last period.) By backward induction, we either find the threshold period where the principal switches from payment to non-payment or strict non-payment turns out to be optimal. Therefore, if trust enhancing payments are optimal within the optimal strategy the principal builds up trust until its desired level right from the beginning and earns the gains from high trust in the remaining periods by not paying the bonus. Here the trust evolution according to the adaptive learning process turns out to be decisive. With only sparse information available to the agent in the beginning, the principal very effectively influences trust by paying the voluntary bonus. Later on the agent will have observed quite a number of bonus payments so that trust becomes robust. In other words, the principal's decisions early in the agency have a stronger impact on the agent's belief than the ones later in the agency. Then the principal can secure higher bonus saving without risking a drastic decrease in the trust level. Keep in mind that the agent cannot verify whether non-payments result from unforeseen contingencies or the principal's decision. Of course, if the agent was able to disentangle the causes, trust would effectively reduce to level zero.

In our model, the agent's adaptive learning process (which is consistent with Bayesian inference) creates effective incentives for trust formation through early payments. ${ }^{18}$ Once the principal decides not to pay the bonus in a period, nonpayments must be optimal in all subsequent periods. As such the strategy pattern which is endogenous equilibrium behavior in our model resembles the grim-trigger strategy that exogenously enters into previous implicit contracting models to sustain an equilibrium.

In each period the agent's compensation contract $W_{t}$ is designed according to Eqs. 2-4 such that he receives exactly his reservation utility in expectation, conditional on trust $\gamma_{t-1}$ at the beginning of the period. In contrast to the classical hidden action approach, uncertainty here results solely from the principal's uncertain payment behavior in the eyes of the agent. Whether or not the agent receives his reservation utility ex post is endogenous in our model: Whenever the principal decides to pay the bonus, the agent receives more than his reservation utility, and whenever she does not pay the agent receives less than it. In light of the principal's optimal strategy derived in Proposition 2, the agent receives a "rent" in

\footnotetext{
18 The same effect occurs if a sample from a normal distribution is used to update the mean of a normally distributed variable: The higher the variance of the prior distribution, the stronger the impact of the sample on the posterior mean.
} 


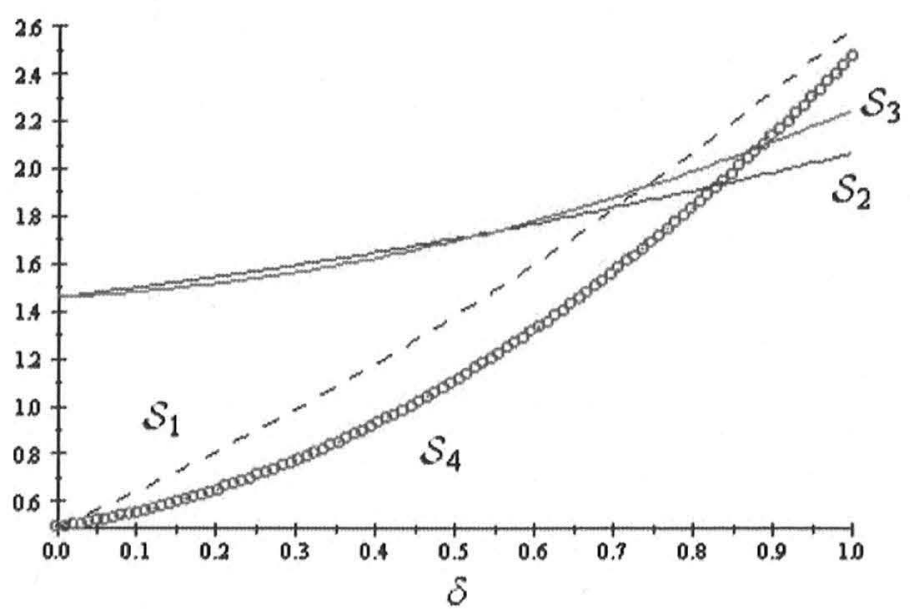

Fig. 1 Surplus levels $\mathcal{S}_{i}$ from strategy $\boldsymbol{\theta}_{\boldsymbol{i}}$ contingent on discount factor $\delta$ : $\boldsymbol{\theta}_{1}=(1,0,0), \boldsymbol{\theta}_{2}=$ $(0,0,0), \theta_{3}=(0,1,0)$, and $\theta_{4}=(1,1,0)$

the first $\tau$ periods of the relationship and loses thereafter. Whether the agent obtains a rent or a loss relative to its reservation utility over the total length of the relationship depends on the specifics of the agency: $r, T$ and $\alpha$ and $\beta$.

The optimality of non-alternating strategies depends on a sufficiently low interest rate (or, sufficiently high discount factor). For high interest rates, earning the gains from trust enhancement lately in the relationship becomes less attractive as future payoffs are worth less. This might direct the principal to early non-payments. At the optimum the principal balances the benefits of early trust formation against its costs in terms of discounting. To clarify the trade-off, consider the following example:

Example 1 Discount rates and optimal strategies

Parameters: $T=3 ; \alpha=1 ; \beta=1 / 100$.

Strategies: $\left\{\boldsymbol{\theta}_{1}=(1,0,0), \boldsymbol{\theta}_{2}=(0,0,0), \boldsymbol{\theta}_{3}=(0,1,0)\right.$, and $\left.\boldsymbol{\theta}_{4}=(1,1,0)\right\}$.

Figure 1 plots the strategy dependent surplus levels $\left(\mathcal{S}_{i} \equiv \mathcal{S}\left(\boldsymbol{\theta}_{i}\right)\right)$ against $\delta$. With infinitely high discounting $(\delta \rightarrow 0)$ strategies $\boldsymbol{\theta}_{2}$ and $\boldsymbol{\theta}_{3}$ are optimal, because both feature non-payment in period 1 (which will not be discounted). Let $\delta$ increase above zero. Initially $\mathcal{S}_{2}$ rises stronger than $\mathcal{S}_{3}$ as the second period payoff under $\boldsymbol{\theta}_{2}$, $S_{2}^{D}\left(\gamma_{1}\right)$, is higher than under $\boldsymbol{\theta}_{3}, S_{2}^{H}\left(\gamma_{1}\right)$. At the same time the effect of payment in the second period on the third period payoff under $\boldsymbol{\theta}_{3}$ does not preponderate because with $\delta$ relatively small the third period payoff is of little value. As $\delta$ is increasing further the effect reverses. Now the advantage of having built up trust in period 2 becomes dominant and strategy $\boldsymbol{\theta}_{3}$ yields a higher surplus than $\boldsymbol{\theta}_{2}$. If the interest rate $r$ becomes sufficiently small, $\delta \rightarrow 1$, the advantage of early trust building appears and $\boldsymbol{\theta}_{1}$ dominates $\boldsymbol{\theta}_{3}$. (Due to the numerical values of the example, $\boldsymbol{\theta}_{4}$ will never be optimal here). What becomes obvious from example 1 is that with $r$ being sufficiently high alternating strategies may become optimal. 


\section{Bounded recall by the agent}

In this section we investigate if and how the principal's optimal decisions change when the agent is not able to recall an arbitrarily long sequence of bonus payments. Technically, the level of trust in any given period $t$ will now depend upon a history of $\tau^{F}$ periods prior to it, where $F$ denotes forgetfulness. Since the level of trust also determines the agent's effort decision, our approach is similar to Mailath and Morris (2006) who define $L$-bounded recall as a strategy profile that does not need the entire history but only the last $L$ signals. To cut-off the history of play at a certain point is a simplification of exponential or power forgetting functions proposed by psychologists, ${ }^{19}$ or can be interpreted as the well-known recency bias in decision analysis. ${ }^{20}$ The crucial change for the principal-compared to the situation in the previous section-is that the decision in a given period $t$ influences future periods only up to period $t+\tau^{F}$, and repercussions from previous decisions are limited to periods $t-$ $\tau^{F}, \ldots, t-1$. For instance, assume $\tau^{F}=3$ and $\alpha=\beta=1$. Then starting with initial trust of $\gamma_{0}=\frac{\alpha}{\alpha+\beta}=\frac{1}{2}$ the evolution of trust assuming decision sequence $(0,1,0,0)$ is given by $\gamma_{1}=\frac{\alpha}{\alpha+\beta+1}=\frac{1}{3}, \gamma_{2}=\frac{\alpha+1}{\alpha+\beta+1+1}=\frac{1}{2}$, and $\gamma_{3}=\frac{1}{1+1}=\frac{1}{2}$, where at the beginning of the fourth period the agent does not recall initial trust but his adaptive learning rests only on the last three periods $(0,1,0)$.

Whenever the principal does not want to pay the voluntary bonus $\tau^{F}$-times in a row trust will be completely destroyed and the agent will choose no effort in the following period..$^{21}$ But what about a non-bonus payment following a period with an effort level of zero? Here we have to clarify what actually constitutes "nonpayment". In the word's literal sense, a zero-bonus payment subsequent to zero effort cannot be non-payment because it accords with promise (not) to pay. However, we consider a zero-bonus payment following zero effort as a period where no implicit agreement could be established; it constitutes non-payment. Hence, the relationship is effectively over after $\tau^{F}$ non-payments in a row.

We consider first the extreme case of $\tau^{F}=1$ and then proceed to $\tau^{F} \geq 2$.

\subsection{One-period recall by the agent}

If the agent recalls only the previous period of the relationship, his projection for the upcoming period will be that the principal will repeat her decision from the previous period. Formally we obtain

\footnotetext{
19 See Wixted (2004) for a review of-and for non-psychologists an introduction into-the topic.

${ }^{20}$ Basu and Waymire (2006) and Basu et al. (2007) show that recordkeeping-e.g., as required by modern accounting systems- enhances trust and therefore enables complex economics transactions. The need for recordkeeping to support memory by the human brain sustains our assumption of limited recall in the first place. As in practice, however, recordkeeping in an employer-employee relationship will not be observed, we do not consider formal recordkeeping as a device to support a more effective recall by the agent.

21 Ittner et al. (2003) provide an empirical example where individual balanced scorecards were removed because employees did not trust the scorecard measures anymore after supervisors ignored a number of them or attached different weights to them from quarter to quarter.
} 


$$
\gamma_{t-1}=\operatorname{Prob}\left(\theta_{t}=1 \mid \theta_{t-1}\right)= \begin{cases}1 & \text { if } \theta_{t-1}=1 \\ 0 & \text { if } \theta_{t-1}=0\end{cases}
$$

and

$$
\left(1-\gamma_{t-1}\right)=\operatorname{Prob}\left(\theta_{t}=0 \mid \theta_{t-1}\right)= \begin{cases}0 & \text { if } \theta_{t-1}=1 . \\ 1 & \text { if } \theta_{t-1}=0\end{cases}
$$

Equations 16 and 17 render alternating strategies infeasible. The following proposition describes the principal's optimal strategy.

Proposition 3 Let $\tau^{F}=1$, then

(a) if $r$ is sufficiently low, the principal's optimal strategy is $\boldsymbol{\theta}=\left(\theta_{1}=\theta_{2}=\right.$ $\cdots=\theta_{T-1}=1, \theta_{T}=0$ ), i.e. to pay the bonus in all but the final period;

(b) if $r$ is sufficiently large, the principal's optimal strategy is $\boldsymbol{\theta}=\mathbf{0}$, i.e., strict non-payment.

Short recall on the side of the agent approximates the cooperative solution very closely if the interest rate is sufficiently low. The reason is that one-period recall puts the highest possible pressure on the principal to behave trustworthy. The principal is forced to pay the bonus as non-payment once prevents employee motivation in all future periods. As such, the optimal strategy is endogenous and resembles the grim-trigger strategy-defect once and cooperative play is ruled out for all future periods - that is usually exogenous to implicit contracting models.

\subsection{Multi-period recall by the agent}

In this section we assume the agent is able to recall the sequence of bonus decisions for $\tau^{F}$ periods, $2 \leq \tau^{F} \ll T$. Limited recall has two fundamental effects. First, if the principal chooses $\tau^{F}$-non-payments in a row she never regains a chance to build up trust, that is, she realizes zero surpluses for all periods to come. Intuitively, if the agent recalls only non-payments, he is disappointed and accepts only zero-bonus contracts. Second, a decision in a given period $t$ influences future periods only up to period $t+\tau^{F}$. Hence, trust reducing non-payments will eventually be cleared from the agent's memory offering a chance for principals to not-pay again.

From previous sections it is straightforward that if the interest rate is very high the principal decides not to pay the bonus in the first period and subsequent periods are immaterial. For $r$ sufficiently small it can never be optimal to select nonpayment $\tau^{F}$-times in a row if there are subsequent periods before the end of the relationship. The principal has to trade-off surpluses from repeated non-payments against those arising from payments based on ceteris paribus higher trust levels. In other words it could be optimal to either frequently switch back and forth between payment and non-payment or to insert only few non-payments into the (otherwise) strict payment strategy.

Now assume there is a time span during which the principal does not pay the bonus $d$ times starting from full trust, i.e., the principal defects $d$ times on her bonus promise. By induction, if it is optimal to choose non-payment in that time span, it 
will again be optimal to do so in periods after full trust has been reestablished by bonus payments.

Definition 4 (Representative sequence) The decision sequence $\theta^{R}\left(\tau^{F}, d\right)$ consisting of $\tau^{F}$ payments and $d>0$ non-payments is called the representative sequence.

Lemma 2 Assume a repetition of the representative sequence $\theta^{R}\left(\tau^{F}, d\right)$ is an element of the principal's optimal strategy: Then, if $r$ is sufficiently small, the number of non-payments $d$ contained in $\theta^{R}\left(\tau^{F}, d\right)$ must be placed in a row, i.e., the representative sequence shows at most one change where the principal switches from payment to non-payment.

Lemma 2 indicates that switching back and forth between one payment and one non-payment cannot be equilibrium behavior, just as it was not under perfect recall either-and for the same reason. Thus the result holds even in light of the agent's bounded recall. This is noteworthy because the latter prevents erosion of marginal gains from payment due to a constant number of $\tau^{F}$ periods for trust formation.

The following proposition describes a principal's optimal strategy pattern for a low interest rate.

Proposition 4 If $r$ is sufficiently small, the optimal strategy pattern is to select the representative sequence $\theta^{R}\left(\tau^{F}, d\right)=\left(\theta_{1}=1, \theta_{2}=1, \ldots, \theta_{\tau^{F}}=1, \theta_{\tau^{F}+1}=0, \ldots\right.$, $\left.\theta_{\tau^{F}+d}=0\right)$ as often as possible given there are at least $\tau^{F}$ periods remaining to harvest full trust. The final periods are subject to separate optimization.

In her optimal strategy the principal induces full trust just at the beginning of the relationship and then absorbs the benefits from perfect trust by not paying the bonus $d$ times in a row. This procedure will be repeated as long as possible, i.e., establishing full trust is optimal as long as there are at least $\tau^{F}$ periods to harvest full trust. The remaining periods exhibit a "last-round effect" for the principalincluding a non-payment in the last period - such that they are subject to separate optimization. It is striking that the optimal strategy pattern under bounded recall consists of a repetition of the one under unbounded recall. Again the principal benefits from early payments placed in a row because trust formation most effectively works this way. Strict payment, however, cannot be optimal and the principal chooses non-payment towards the end of the representative sequence. Like one-period recall, multi-period bounded recall also increases the pressure for the principal to keep the bonus promise because after $\tau^{F}$ non-payments trust is destroyed for the rest of the agency. Yet bounded recall enables her to harvest full trust several times. With unbounded recall, in contrast, approaching full trust will never be observed as marginal trust gains decrease in the number of bonus payments (see Eq. 1).

Based on the optimal number of non-payments $d$ within the representative sequence and the number of periods the agent recalls, we define two trust levels.

Definition 5 (Optimal trust) The average level of trust in the representative sequence is called the optimal level of trust in the agency, $\gamma^{\text {opt }}=\frac{\tau^{F}}{d+\tau^{r}}$. 
Definition 6 (Critical trust level) The level of trust the principal will not go below is called the critical level of trust in the agency, $\gamma^{\text {crit }}=\frac{\tau^{F}-d}{\tau^{F}}$.

Obviously, the optimal trust level never falls short of the critical trust level (unless $d=0$ ). One may suppose that maintaining full trust by keeping promises to pay the bonus becomes too costly so that the optimal trust level does not match the full trust level. In contrast, it should pay for the principal to ensure the agent keeps "positive expectations" concerning her behavior.

Proposition 5 The number of non-payments $d$ contained in the representative sequence $\theta^{R}\left(\tau^{F}, d\right)$ is weakly stepwise increasing in $\tau^{F}$, the number of periods the agent recalls.

Corollary 1 If $\tau^{F}=1$, it follows $\gamma^{o p t}=\gamma^{\text {crit }}=1$. If $\tau^{F}>1$, it follows $\gamma^{o p t}<1$ and $\gamma^{\text {crit }} \geq \frac{1}{2}$; both weakly increase in $\tau^{F}$ with rollbacks when the optimal $d$ increases by 1 .

The optimal level of trust is generally lower than 1 while a minimum trust level of $1 / 2$ will be maintained at all times. Given the discrete nature of the principal's decisions, neither the optimal level of trust nor the critical level of trust is monotone in $\tau^{F}$, the number of periods the agent recalls. Both increase in $\tau^{F}$ with rollbacks whenever an additional non-payment becomes optimal.

Before a numerical example highlighting the results from propositions 4 and 5 will be presented in example 2 , an intuitive explanation for the propositions and its proofs should be given. If full trust is based on only a few observations then non-payment will destroy trust severely, whereas the adverse impact of nonpayment becomes less severe if full trust is based on a larger number of observations. For example, if $\tau^{F}=2$, non-payment (after full trust has been reestablished) reduces the level of trust from $2 / 2$ to just $1 / 2$; compare it with $\tau^{F}=10$ : non-payment after full trust has been reestablished lowers trust from 10/ 10 to $9 / 10$. Therefore, additional non-payment(s) may be optimal if the number of periods the agent recalls increases. The fact that the number of optimal nonpayments increases only weakly in the number of periods the agent recalls leads to non-monotonicity of the optimal and the critical level of trust, respectively, in the agency. Therefore, equal values of these levels can be reconciled with quite different degrees of the agent's bounded rationality, i.e., how able he is to recall sequences of bonus decisions.

Example 2 Strategies and payoffs under bounded recall

Parameters: $T=30 ; \alpha=\beta=5 ; \delta_{1}=0.909 ; \delta_{2}=1$.

Discounting is either sufficiently low $\left(\delta_{1}\right)$ to ensure that building up trust is potentially viable, or irrelevant $\left(\delta_{2}\right)$. Table 1 compares strategy contingent payoffs if the history of play the agent recalls amounts to $\tau^{F}=2(4 ; 6)$ periods, respectively. Optimal strategies are highlighted in bold. Based on the calculations in Table 1, the optimal level of trust and the critical level of trust for different numbers of periods the agent recalls obtain as given in Table 2 . Note the rollback in these levels when $\tau^{F}$ increases from 5 to 6 . 
Table 1 Strategies and payoffs under limited recall (Optimal strategies in bold)

\begin{tabular}{|c|c|c|c|c|}
\hline \multirow{2}{*}{$\frac{\tau^{F}}{2}$} & \multicolumn{2}{|c|}{ Strategy profile* $\left(\theta_{1} ; \theta_{2} ; \ldots ; \theta_{30}\right)$} & \multirow{2}{*}{$\frac{\mathcal{S}\left(\delta_{1}\right)}{4.11}$} & \multirow{2}{*}{$\frac{\mathcal{S}\left(\delta_{2}\right)}{15.24}$} \\
\hline & 1 & $29 \times 1 ; 0$ & & \\
\hline & 2 & $2 \times 1 ; 13 \times\{0,1\} ; 1 ; 0$ & 3.08 & 9.46 \\
\hline & 3 & $10 \times\{2 \times 1 ; 0\}$ & 5.02 & 17.24 \\
\hline \multirow[t]{4}{*}{4} & 4 & $27 \times 1 ; 3 \times 0$ & 3.82 & 14.95 \\
\hline & 5 & $4 \times 1 ; 12 \times\{0 ; 1\} 3 \times 0$ & 3.36 & 9.86 \\
\hline & 6 & $6 \times\{4 \times 1 ; 0\}$ & 4.34 & 15.78 \\
\hline & 7 & $5 \times\{4 \times 1 ; 0 ; 0\}$ & 4.30 & 15.38 \\
\hline \multirow[t]{6}{*}{6} & 8 & $27 \times 1 ; 3 \times 0$ & 3.55 & 14.77 \\
\hline & 9 & $6 \times 1 ; 11 \times\{0 ; 1\} ; 0 ; 0$ & 3.37 & 10.36 \\
\hline & 10 & $4 \times\{6 \times 1 ; 0\} ; 0 ; 0$ & 3.89 & 15.29 \\
\hline & 11 & $2 \times\{6 \times 1 ; 0 ; 0\} ; 6 \times 1 ; 0 ; 4 \times 1 ; 3 \times 0$ & 3.92 & 14.57 \\
\hline & 12 & $2 \times\{6 \times 1 ; 0 ; 0\} ; 6 \times 1 ; 5 \times 1 ; 3 \times 0$ & 3.91 & 15.02 \\
\hline & 13 & $2 \times\{6 \times 1 ; 3 \times 0\} ; 9 \times 1 ; 3 \times 0$ & 3.88 & 14.60 \\
\hline
\end{tabular}

* Hint: A strategy profile reads as follows: $2 \times\{6 \times 1 ; 0 ; 0\} ; 11 \times 1 ; 3 \times 0$ play sequence of 6 payments and 2 non-payments twice, then 11 payments and 3 non-payments

Table 2 Optimal trust and critical trust

\begin{tabular}{lllllll}
\hline$\tau^{F}$ & 1 & 2 & 3 & 4 & 5 & 6 \\
\hline Optimal trust & 1 & $2 / 3$ & $3 / 4$ & $4 / 5$ & $5 / 6$ & $3 / 4$ \\
Critical trust & 1 & $1 / 2$ & $2 / 3$ & $3 / 4$ & $4 / 5$ & $5 / 8$ \\
\hline
\end{tabular}

The optimal strategies have three features in common: (1) at the beginning, full trust is established; (2) the representative sequence is repeated as often as possible; (3) the final periods are subject to separate optimization. For $\tau^{F}=\{2 ; 4\}$, the optimal number of non-payments $d$ within the representative sequence is 1 . For example, strategy 7 having two non-payments within the representative sequence is inferior to strategy 6 , the (optimal) strategy with one non-payment. If $\tau^{F}=6, d$ increases to 2. Taken together, $d$ is weakly increasing in $\tau^{F}$. Also note that the final periods of play — decisions noted after braces - are subject to separate optimization. Specifically, compare strategies 11 and 12 . With discounting given by $\delta_{1}=0.909$, strategy 11 is preferred to 12 showing a non-payment after reestablishing full trust subsequent to completing the representative sequence twice. Without discounting strategy 12 starting with additional payments and ending with non-payments is superior to the alternating strategy in 11 .

Note, the optimal alternating strategies under limited recall of at least two periods of play, $\tau^{F} \geq 2$, correspond to trigger strategies like "defect $d+1$ times in a row and cooperative play is ruled out for all future periods". As $d$ is weakly increasing in $\tau^{F}$, the optimal strategies form a subset of trigger strategies that is usually treated as exogenous in implicit contract models. Our model derives these strategies endogenously. 


\section{Interpretation, application and extensions}

The findings of propositions 2 and 4 predict that if trusting relationships are to be established, strategic principals must optimally start with a sequence of voluntary bonus payments. By initial payments trust can be built up as quickly as possible. One could object that trust formation proceeds in a rather slow process because it takes experience to get to high trust. However, empirical research supports the fast process of high trust formation; experience represents the major factor later on in the relationship. ${ }^{22}$ The principal's equilibrium behavior stipulates consecutive nonpayments towards the end of the relationship. Such an experience could lead the agent to think that the non-payment is no longer the outcome of Bernoulli trials but constitutes deliberate behavior of the principal. Hence, trust would vanish and proposition 2 would not have much empirical relevance. An extension of our model by assuming that the agent leaves if he observes too many non-payments is likely to predict fewer non-payments while perpetuating the optimal strategy pattern.

Empirical research suggests trust between employee and supervisor (Ittner et al. 2003) or trust in the agency in general (Hedge 2000) as a crucial influence on the acceptance of performance appraisal systems. Although the model presentation and interpretation so far focuses on subjective performance measures, similar concerns can be expected even if verifiable accounting measures are used for performance appraisals. As Hopwood (1972, p. 157) notes, accounting performance measurement systems (PMS) can often be improved but not as much to achieve the "ideal system", which would correctly mirror all dimensions of employee performance. As a consequence, even accounting information should be used with discretion in performance evaluation. ${ }^{23}$ Here, numbers or outcomes may not be disputed but the cause of numbers (Campbell et al. 1998, p. 133). Taking this insight into our model, both principal and agent agree on observed agent effort or performance and if it was a verifiable accounting number a contract could be written on it. But if agent motivation depends on his willingness to accept the cause, his trust in the performance evaluation process would be important. A just and transparent evaluation will certainly foster trust in that respect.

In our model, bonus payments increase trust which in turn leads to higher performance. Such trust in the principal's willingness to pay can also be identified as trust in the PMS, i.e. the likelihood that (perceived) individual performance and performance appraisal coincide. For that purpose, $E(\gamma)$, the probability that the principal pays the bonus at the end of the period would have to be reinterpreted as the level of trust the agent puts into the performance evaluation process. In line with empirical evidence (Folger and Konovsky 1989), the importance of transparent and fair performance appraisals has been pointed out by several authors, e.g., Baker (1990) or Milkovich and Newman (2002, p. 302). The present model formalizes benefits of such a trust "investment"-the principal's decision to pay a bonus could be seen as an investment -, but the fact that optimal strategies include non-payments

\footnotetext{
${ }^{22}$ See McKnight et al. (1998) for a (non-analytical) model of initial trust formation and the references to empirical findings therein.

${ }^{23}$ See also Murphy and Oyer (2003).
} 
(propositions 2,4) suggests that definite fairness or transparency of PMS cannot be an objective for firms. Therefore, disagreements of employees with their performance appraisals (Campbell and Lee 1988) are likely to persist. Or, achieving and maintaining maximum trust is not in every case viable. Although this may sound trivial it is actually not. Ittner and Larcker (2003) report that not setting the right performance targets represents a common mistake in nonfinancial performance measurement. In their study, for example, managers tried to achieve $100 \%$ customer satisfaction because they believed it would pay off. A prominent example of maximum trust is (or used to be) the practice of lifetime employment by Japanese firms which analysts believe to represent a too heavy financial burden. ${ }^{24}$

One could interpret the average level of trust prevalent in exchange relationships as optimal trust (Wicks et al. 1999). We explicitly determine such an optimal level of trust in Sect. 4 on bounded recall. We also identify a critical level of trust that firms optimally do not go below (corollary 1). Both the optimal and the critical level of trust $\left(\gamma^{\text {opt }}, \gamma^{\text {crit }}\right)$ increase in the number of periods the agent recalls. If -in empirical research-the latter is proxied by tenure in the firm, then longer tenure translates into higher trust levels which in turn increase the surpluses generated by the employer-employee relationship. Or, in other words, subjective incentives become more effective. As such our model provides an analytical rationale for Gibbs et al.'s (2004) empirical finding that subjective incentives can be more effective when trust-proxied by tenure - is higher.

Besides forgetfulness limiting the number of periods which determine trust relevant for a particular period, one could also think of trust as a replaceable intangible asset with finite life of $\tau^{F}$-periods (Mailath and Samuelson 2001). Consider rapidly changing environments which are likely to be represented by a shorter "life" of trust, i.e., investments in trust would be needed more often. Since optimal trust $\gamma^{\mathrm{opt}}$ is increasing in $\tau^{F}$ (corollary 1), an additional prediction emerging from the analysis is that in rapidly changing environments, possibly manifested by repeated restructuring and/or managerial turnover, the optimal level of trust is lower than in stable environments. (Note that investments in trust are viable in both scenarios.) In fact, there is some empirical evidence (Robinson 1996; Robinson and Rousseau 1994) that globalization and organizational restructuring have lead to more frequent breach of implicit contracts or the so-called psychological contract. ${ }^{25}$ However, the analysis in this paper also suggests that trust measurement in employer-employee relations could come to equal results in differently stable environments because optimal trust as well as critical trust are not monotone in the parameter $\tau^{F}$. Interpreting that parameter as the degree of the agent's bounded rationality, again equal trust measures can go hand in hand with different degrees of bounded rationality.

In recent papers Basu and Waymire (2006) and Basu et al. (2007) emphasize the benefits of recordkeeping in complex economic transactions. Basu et al. (2007) show in a complex multi-period trust game experiment that recordkeeping leads to

\footnotetext{
${ }^{24}$ Cf. Wicks et al. (1999), p. 101.

${ }^{25}$ According to Rousseau (1990, p. 390), a psychological contract are individual beliefs regarding reciprocal obligations.
} 
higher trust and induces higher reciprocity. If recordkeeping is possible (in the experiment) the trustor (investor) better recalls past transactions and trust formation by higher reciprocity of the trustee shows. In contrast to these papers we demonstrate that bounded recall by the employee may lead the employer to pay the bonus more often such that higher trust is induced. As the employee refuses cooperation for all future if he only recalls breaches of contract, shorter recall by the agent forces the principal to reciprocate more often. ${ }^{26}$

Adding more structure to the model would allow us to further clarify the dependence of optimal and critical trust on other parameters and to derive more testable hypotheses. Such extended model specifications could then be tested in the laboratory. An interesting feature of the model carrying over to them is the range of possible trust levels because experimental trust games usually allow only for the alternative to fully trust or not trust at all.

\section{Summary and conclusion}

In this paper we analyze a multi-period employer-employee relationship in which bonus payments by the employer are not enforceable. The employee (agent) does not know whether his employer (principal) pays bonuses only strategically or if she always pays bonuses. The results of our paper relate to contract design and implicit incentives both from a theoretical perspective as well as from a practical perspective. First of all we introduce an evolution of trust into the standard implicit contract model. The distributional assumption how trust evolves with (non)payment decisions by the principal allows for adaptive learning on the side of the agent and covers quite different ex ante evaluations about the trustworthiness of the principal. The agent is assumed to be characterized by bounded rationality, and unforeseeable contingencies prevent that he can unambiguously identify his principal's nature. These two assumptions give rise to rely on trust as part of contracts in the first place. The equilibria we derive and which have empirical support cannot be obtained under the assumption of the fully rational agent.

As long as the agent is able to recall the entire sequence of bonus decisions, nonalternating strategies are optimal, i.e. a strategic principal builds up trust in early periods by paying the voluntary bonus (if that is ever optimal) and then harvest the benefits from high trust by not paying the bonus in later periods. If discounting is high, alternating strategies may become optimal. We further show that higher levels of ex ante trust increase the expected surplus of the agency and can at least partially offset the negative effect of a high interest rate on the viability of trust enhancing bonus payments.

In an extension of the model where agents cannot recall the entire history of play, we show that the fewer periods the agent is able to recall the higher the pressure for the principal to keep the bonus promise. Within a representative decision sequence that accounts for the agent's forgetfulness the same strategy pattern as under unbounded recall turns out to be optimal. However, as the principal's optimal

\footnotetext{
${ }^{26}$ Cf. optimal trust for $\tau^{F}=\{4,6\}$ in Table 2 .
} 
strategy exhibits repetitions of the representative sequence we also demonstrate optimality of alternating strategies. That is, the principal switches back and forth between payment and non-payment. Here a subset of trigger strategies that is usually exogenous to implicit contracting models can be derived endogenously, thus offering some justification for the conventional approach. These strategies imply an average level of trust in an agency that increases in the number of periods the agent recalls. As such we formalize the idea of optimal trust suggested by Wicks et al. (1999). An interesting and important interpretation of the analysis relates to performance measurement systems and performance appraisals. Although transparency, fairness and understandability are important to make performance measurement systems work-that is, employees trust the process or system - attaining or maintaining definite transparency and understandability is not in every case viable as it may become too costly. With increasing tenure of employees subjective performance measures become more effective. We substantiated our claim that these issues need to be taken into account even if verifiable accounting numbers are available.

This paper suggests a model for the formal analysis of a trust relationship between two parties. An agent trusts a principal to pay him a bonus. Observability of agent effort puts the principal's trust in the agent aside; it is therefore a one-sided trust relationship. Extending it by including non-observability of agent effort such that the principal needs to trust the agent to expend the desired effort level (in the absence of verifiable performance measures), a two-sided trust relationship would result. One could also think of path-dependent trust evolution, i.e., not just the number of (non)payments determines the level of trust but also the specific pattern of these (non)payments. A third possible extension could be to include control as a matter of choice by the principal. It seems worthwhile and promising to add more structure to the model in these respects. Also, these model extensions then lead to empirical predictions beyond the ones we propose, and experimental research as well as field research could provide in-depth tests of these.

Acknowledgments We thank Holger Asseburg, Oliver Fabel, Alfred Luhmer, Barbara SchöndubePirchegger, Jack Stecher, the editor, two anonymous referees, and audiences at Bonn, Milan, and Rotterdam for helpful comments.

\section{Appendix}

\section{Proof of Proposition 1}

(a) Differentiating $\mathcal{S}(\boldsymbol{\theta})$ as given by Eq. 13 with respect to $\delta$ we obtain $\frac{\partial \mathcal{S}(\boldsymbol{\theta})}{\partial \delta}=\sum_{t=1}^{T} S_{t}(\boldsymbol{\theta})(t-1) \delta^{t-2}>0$. As $\frac{\partial \delta}{\partial r}=-i(1+r)^{-(i+1)}<0$ it follows $\frac{\partial \mathcal{S}(\boldsymbol{\theta})}{\partial r}<0$. Let $\boldsymbol{\theta}^{*}$ be the optimal strategy with $r$ and $\boldsymbol{\theta}^{\prime}$ the optimal strategy with $r^{\prime}>r$. As $\mathcal{S}(\boldsymbol{\theta})$ is decreasing in $r, \mathcal{S}\left(\boldsymbol{\theta}^{\prime}, r^{\prime}\right)<\mathcal{S}\left(\boldsymbol{\theta}^{\prime}, r\right)$, and as $\mathcal{S}\left(\boldsymbol{\theta}^{\prime}, r\right)<\mathcal{S}\left(\boldsymbol{\theta}^{*}, r\right)$ it follows $\mathcal{S}\left(\boldsymbol{\theta}^{\prime}, r^{\prime}\right)<\mathcal{S}\left(\boldsymbol{\theta}^{*}, r\right)$ and the principal's equilibrium payoff decreases in $r$.

(b) Consider period $t$ with induced trust $\gamma_{t-1}$. If non-payment is optimal in period $t$ with interest rate $r$, given $\gamma_{t-1}$, then non-payment must be optimal in period $t$ 
with $r^{\prime}>r$ given $\gamma_{t-1}$, too, as the surplus function (or equivalently: the left hand side of the non-reneging constraint Eq. 12) is decreasing in $r$. Hence, starting with the same initial level of trust, $\gamma_{0}$, the induced level of trust in period $t$ with interest rate $r, \gamma_{t-1}^{r}$, must be at least as high as with $r^{\prime}>r$, i.e., $\gamma_{t-1}^{r} \geq \gamma_{t-1}^{r^{\prime}}$ for all $t$; for $\gamma_{t-1}^{r}<\gamma_{t-1}^{r^{\prime}}$ to be true for some period $t$ there must have been a period $\tau<t$ with $\gamma_{\tau-1}^{r}=\gamma_{t-1}^{r^{\prime}}$ and with non-payment for $r$ but payment for $r^{\prime}$ : a contradiction. Hence, the number of periods $\sum_{i=1}^{t} \theta_{i}$ in which the bonus is paid up to some period $t$ is weakly decreasing in $r$.

(c) A higher level of ex ante trust increases every summand in Eq. 13 such that $\mathcal{S}$ is increasing in $\gamma_{0}$.

Proof of Lemma 1 Writing payoffs $S_{t}$ as a function of induced trust $\gamma_{t-1}$ at the beginning of period $t$ transforms Eq. 13 into $\mathcal{S}^{D}=\sum_{t=1}^{T} S_{t}^{D}\left(\gamma_{t-1}^{0}\right) \delta^{t-1}$ for strict nonpayment, $\boldsymbol{\theta}=\mathbf{0}$, and $\mathcal{S}^{H}=\sum_{t=1}^{T} S_{t}^{H}\left(\gamma_{t-1}^{1}\right) \delta^{t-1}$ for strict payment, $\boldsymbol{\theta}=\mathbf{1}$, where $\gamma_{t-1}^{\boldsymbol{\theta}}$ indicates the level of trust at the beginning of period $t$ contingent on $\boldsymbol{\theta} \in\{\mathbf{0}, \mathbf{1}\}$. To show how $\mathcal{S}^{D}$ and $\mathcal{S}^{H}$ behave depending on the principal's lifetime $T$ we write them explicitly as a function of $T, \mathcal{S}^{D}(T)$ and $\mathcal{S}^{H}(T)$. For expositional brevity assume $T$ is continuous. Surpluses become $\mathcal{S}^{D}(T)=\int_{t=1}^{T} S_{t}^{D}\left(\gamma_{t-1}^{0}\right) \delta^{t-1} d t$ and $\mathcal{S}^{H}(T)=$ $\int_{t=1}^{T} S_{t}^{H}\left(\gamma_{t-1}^{1}\right) \delta^{t-1} d t$. The first derivatives with respect to $T$ obtain as

$$
\frac{d \mathcal{S}^{D}(T)}{d T}=S_{T}^{D}\left(\gamma_{T-1}^{0}\right) \delta^{T-1}>0 ; \quad \frac{d \mathcal{S}^{H}(T)}{d T}=S_{T}^{H}\left(\gamma_{T-1}^{1}\right) \delta^{T-1}>0 ;
$$

and second derivatives as

$$
\begin{aligned}
\frac{d^{2} \mathcal{S}^{D}(T)}{d T^{2}} & =\delta^{T-1} \frac{d S_{T}^{D}}{d \gamma_{T-1}^{0}} \frac{d \gamma_{T-1}^{\mathbf{0}}}{d T}+S_{T}^{D}\left(\gamma_{T-1}^{\mathbf{0}}\right) \delta^{T-1} \ln (\delta) \\
\frac{d^{2} \mathcal{S}^{H}(T)}{d T^{2}} & =\delta^{T-1} \frac{d S_{T}^{H}}{d \gamma_{T-1}^{1}} \frac{d \gamma_{T-1}^{1}}{d T}+S_{T}^{H}\left(\gamma_{T-1}^{\mathbf{1}}\right) \delta^{T-1} \ln (\delta) .
\end{aligned}
$$

Notice that according to (1)

$$
\begin{aligned}
& \gamma_{T-1}^{0}=\frac{\alpha}{\alpha+\beta+T-1} \\
& \gamma_{T-1}^{1}=\frac{\alpha+T-1}{\alpha+\beta+T-1}
\end{aligned}
$$

such that $\frac{d \gamma_{T-1}^{0}}{d T}=-\frac{\alpha}{(\alpha+\beta+T-1)^{2}}<0$ and $\frac{d \gamma_{T-1}^{1}}{d T}=\frac{\beta}{(\alpha+\beta+T-1)^{2}}>0$. Furthermore, we know from Eqs. 14 and 15 that $\frac{d S_{T}^{D}}{d \gamma_{T-1}^{0}}>0$ and $\frac{d S_{T}^{H}}{d \gamma_{T-1}^{1}}>0$. Assuming $r=0$, i.e., $\delta=1$ leading to $\ln (\delta)=0$, it follows that $\mathcal{S}^{D}(T)$ is a strictly monotone increasing concave function of $T$ and $\mathcal{S}^{H}(T)$ is a strictly monotone increasing convex function of T. Furthermore we know that $\mathcal{S}^{D}(1)>\mathcal{S}^{H}(1)$ and $\lim _{T=\infty} \frac{d \mathcal{S}^{D}(T)}{d T}=0$ and $\lim _{T=\infty} \frac{d \mathcal{S}^{H}(T)}{d T}=1 / 2$. Hence, there exists a threshold value for $T$ such that strict 
payment dominates strict non-payment. The same result applies for positive but sufficiently small $r$.

Proof of Proposition 2 Assume $r=0$ and consider strategy $\boldsymbol{\theta}^{\prime}=(\ldots, 0,1, \ldots)$ where the principal does not pay the bonus in period $\tau$ but does pay it in $\tau+1$. Now consider strategy $\boldsymbol{\theta}=(\ldots, 1,0, \ldots)$ where the principal pays in $\tau$ and does not pay in period $\tau+1$. Everything else equal we can compare strategies $\boldsymbol{\theta}^{\prime}$ and $\boldsymbol{\theta}$ by comparing their ex ante expected payoffs from period $\tau$ and $\tau+1$. We obtain

$$
\begin{aligned}
\mathcal{S}(\boldsymbol{\theta}) & =S_{\tau}^{H}\left(\gamma_{\tau-1}\right)+S_{\tau+1}^{D}\left(\gamma_{\tau}\right) \\
\mathcal{S}\left(\boldsymbol{\theta}^{\prime}\right) & =S_{\tau}^{D}\left(\gamma_{\tau-1}\right)+S_{\tau+1}^{H}\left(\gamma_{\tau}^{\prime}\right) .
\end{aligned}
$$

$\gamma_{\tau-1}$ is the level of trust induced at the beginning of period $\tau, \gamma_{\tau}\left(\gamma_{\tau}^{\prime}\right)$ is the level of trust at the beginning of period $\tau+1$ given payment (non-payment) in $\tau$. We know that $\gamma_{\tau}>\gamma_{\tau-1}>\gamma_{\tau}^{\prime}$. The difference of expected payoffs is

$$
\mathcal{S}(\boldsymbol{\theta})-\mathcal{S}\left(\boldsymbol{\theta}^{\prime}\right)=\left[S_{\tau}^{H}\left(\gamma_{\tau-1}\right)-S_{\tau+1}^{H}\left(\gamma_{\tau}^{\prime}\right)\right]+\left[S_{\tau+1}^{D}\left(\gamma_{\tau}\right)-S_{\tau}^{D}\left(\gamma_{\tau-1}\right)\right]
$$

As $S^{D}$ and $S^{H}$ are increasing in $\gamma$, both brackets [.] are strictly positive and therefore $\mathcal{S}(\boldsymbol{\theta})-\mathcal{S}\left(\boldsymbol{\theta}^{\prime}\right)>0$. By induction, this argument also holds for any number $\tau$ of nonpayments in a row. As long as $r$ is sufficiently low the same logic applies for $r>0$. Hence, if discounting is low and the principal's optimal strategy exhibits $\tau$ payments, the optimal strategy pattern is $\boldsymbol{\theta}^{*}=\left(\theta_{1}=1, \theta_{2}=1, \ldots, \theta_{\tau}=1\right.$, $\left.\theta_{\tau+1}=0, \ldots, \theta_{T}=0\right)$ : Trust will be raised to its desired maximum until period $\tau$ and in the remaining periods the gains from trust formation will be earned by nonpayments.

\section{Proof of Proposition 3}

(a) The surplus Eq. 13 for strategy $\boldsymbol{\theta}^{*}=\left(\theta_{1}=1, \theta_{2}=1, \ldots, \theta_{T-1}=1, \theta_{T}=0\right)$ obtains as

$$
\begin{aligned}
\mathcal{S}\left(\boldsymbol{\theta}^{*}\right) & =S_{1}^{H}\left(\gamma_{0}\right)+\sum_{t=2}^{T-1} S_{i}^{H}\left(\gamma_{t-1}=1\right) \delta^{t-1}+S_{T}^{D}\left(\gamma_{T-1}=1\right) \delta^{T-1} \\
& =\frac{\gamma_{0}}{2\left(2-\gamma_{0}\right)}+\frac{1}{2} \sum_{t=2}^{T-1} \delta^{t-1}+\frac{3}{2} \delta^{T-1},
\end{aligned}
$$

where $\gamma_{0}$ denotes the prior level of trust. In the final period, the principal will not pay the bonus, i.e. $\theta_{T}=0$, because $S_{T}^{D}\left(\theta^{T-1}\right) \geq S_{T}^{H}\left(\theta^{T-1}\right)$ for any history of play. Since alternating strategies are ruled out by Eq. 16, any strategy that has $\theta_{1}=0$, leads to a surplus of $\mathcal{S}\left(\theta_{1}=0, \theta_{2}=0, \ldots, \theta_{T}=0\right)=\frac{\gamma_{0}\left(4-\gamma_{0}\right)}{\left.2\left(2-\gamma_{0}\right)^{2}\right)}<\frac{3}{2}$, which is clearly dominated by $\mathcal{S}\left(\boldsymbol{\theta}^{*}\right)$ if $r$ is sufficiently low ( $\delta$ sufficiently close to 1 ). A strategy $\boldsymbol{\theta}^{\tau}=\left(\boldsymbol{\theta}_{1}=\mathbf{1}, \theta_{2}=1, \ldots, \theta_{\tau}=1, \theta_{\tau+1}=0, \ldots, \theta_{T}=0\right), 2 \leq \tau \leq T-1$, leads to a surplus $\mathcal{S}\left(\boldsymbol{\theta}^{\tau}\right)=\frac{\gamma_{0}}{\left.2\left(2-\gamma_{0}\right)\right)}+\frac{1}{2} \sum_{t=2}^{\tau} \delta^{t-1}+\frac{3}{2} \delta^{\tau}$. Hence, $\mathcal{S}\left(\boldsymbol{\theta}^{*}\right)-\overline{\mathcal{S}}\left(\boldsymbol{\theta}^{\tau}\right)=\frac{1}{2} \sum_{t=\tau+1}^{T-1} \delta^{t-1}$ $-\frac{3}{2}\left(\delta^{\tau}-\delta^{T-1}\right)$ is positive for all $\tau \leq T-1$ if $r$ is sufficiently low.

(b) If $r$ is sufficiently large, only the first period payoff of the surplus function matters. The first period payoff is maximized by non-payment, $\theta_{1}=0$. 
Proof of Lemma 2 Assume $r=0$. Consider a representative sequence $\theta^{R}\left(\tau^{F}, 1\right)$ consisting of $\tau^{F}$ payments and one non-payment. The surplus ${ }^{27}$ from the second or higher repetition of the representative sequence $\theta^{R}\left(\tau^{F}, 1\right)$ is independent of the period in which the non-payment is placed within $\theta^{R}\left(\tau^{F}, 1\right)$. At each payment the agent recalls $\tau^{F}-1$ payments and one non-payment, and in the period of nonpayment the agent recalls $\tau^{F}$ payments (full trust). The surplus is equal to $\mathcal{S}=\tau^{F} S^{H}\left(\frac{\tau^{F}-1}{\tau^{F}}\right)+S^{D}(1) .^{28}$

Now assume a second non-payment is optimal, $d=2$. We consider two different strategies in placing the second non-payment. In strategy A it is placed immediately after the first non-payment, and in strategy $B$ the two non-payments are not placed in a row. The surpluses related to strategies $A$ and $B$ are given by

$$
\begin{aligned}
& \mathcal{S}^{A}=S^{D}(1)+S^{D}\left(\frac{\tau^{F}-1}{\tau^{F}}\right)+\left(\tau^{F}-1\right) S^{H}\left(\frac{\tau^{F}-2}{\tau^{F}}\right)+S^{H}\left(\frac{\tau^{F}-1}{\tau^{F}}\right) \\
& \mathcal{S}^{B}=2 S^{D}\left(\frac{\tau^{F}-1}{\tau^{F}}\right)+\left(\tau^{F}-2\right) S^{H}\left(\frac{\tau^{F}-2}{\tau^{F}}\right)+2 S^{H}\left(\frac{\tau^{F}-1}{\tau^{F}}\right)
\end{aligned}
$$

The difference of surpluses is $\mathcal{S}^{A}-\mathcal{S}^{B}=S^{D}(1)-S^{D}\left(\frac{\tau^{F}-1}{\tau^{\tau^{F}}}\right)-\left(S^{H}\left(\frac{\tau^{F}-1}{\tau^{F}}\right)-\right.$ $\left.S^{H}\left(\frac{\tau^{F}-2}{\tau^{F}}\right)\right)$. Notice that $1-\frac{\tau^{F}-1}{\tau^{F}}=\frac{\tau^{F}-1}{\tau^{F}}-\frac{\tau^{F}-2}{\tau^{F}}=\frac{1}{\tau^{F}}$. As both $S^{D}$ and $S^{H}$ are increasing convex functions of $\gamma_{(\text {()) }}$, and as for the marginal surpluses it holds $S^{D^{\prime}}>S^{H^{\prime}}$ for all $\gamma_{(\cdot)}, \mathcal{S}^{A}-\mathcal{S}^{B}$ is strictly positive. Hence, if a second non-payment is optimal it must be placed immediately after the first non-payment. The same argumentation applies if $d>2$ non-payments are optimal. Hence, if a repetition of representative sequences $\theta^{R}\left(\tau^{F}, d\right)$ is consistent with equilibrium behavior, $d$ nonpayments must be placed in a row such that there is at most one change from payment to non-payment within a representative sequence. For positive but sufficiently low $r$ the same result applies.

Proof of Proposition 4 Assume $r=0$ for the whole proof. The proof consists of three steps:

(a) We first prove that, independent of the initial trust $\gamma_{0}$ at the beginning of the first period, it is always optimal to establish full trust right from the beginning of the relationship by selecting $\tau^{F}$ payments in a row.

(b) We next prove that given full trust has been established right from the beginning of the relationship at least one non-payment is optimal.

(c) Finally, we show that repetition of the representative sequence is optimal.

(a) Assume $T>2 \tau^{F}$. We first show that strategy $\boldsymbol{\theta}\left(\tau^{F}, \mathbf{0}\right)=\left(\theta_{1}=\theta_{2}=\cdots=\right.$ $\left.\theta_{\tau^{F}}=1,0,0, \ldots, 0\right)$, i.e., fulfill $\tau^{F}$ periods and then never again, dominates all

\footnotetext{
${ }^{27}$ After the representative sequence has been played once, the surplus is the same for every future repetition due to the agent's bounded recall.

${ }^{28}$ We suppress time indices in the surpluses of a representative sequence. Without discounting, the surplus is uniquely determined by the number of payments/non-payments in the sequence and the trust prevailing at these decisions.
} 
strategies $\boldsymbol{\theta}\left(\boldsymbol{\tau}^{F}-\mathbf{i}, \mathbf{0}\right)=\left(\theta_{1}=\theta_{2}=\cdots=\theta_{\tau^{F}-i}=1,0,0, \ldots, 0\right), i=1, \ldots, \tau^{F}-1$ if $\gamma_{0}<1$. Strategy $\boldsymbol{\theta}\left(\tau^{F}, \mathbf{0}\right)$ yields the surplus ${ }^{29}$

$$
\mathcal{S}\left(\boldsymbol{\theta}\left(\boldsymbol{\tau}^{F}, \mathbf{0}\right)\right)=\sum_{t=1}^{\tau^{F}} S^{H}\left(\theta^{t-1}\right)+\sum_{t=\tau^{F}+1}^{2 \tau^{F}} S^{D}\left(\theta^{t-1}\right),
$$

whereas strategy's $\boldsymbol{\theta}\left(\tau^{F}-\mathbf{i}, \mathbf{0}\right)$ surplus obtains as

$$
\mathcal{S}\left(\boldsymbol{\theta}\left(\tau^{F}-\mathbf{i}, \mathbf{0}\right)\right)=\sum_{t=1}^{\tau^{F}-i} S^{H}\left(\theta_{i}^{t-1}\right)+\sum_{t=\tau^{F}-i}^{2 \tau^{F}-i} S^{D}\left(\theta_{i}^{t-1}\right),
$$

where the subscript $i$ at $\theta_{i}^{t-1}$ indicates the history under $\boldsymbol{\theta}\left(\tau^{F}-\mathbf{i}, \mathbf{0}\right)$ compared with $\boldsymbol{\theta}\left(\tau^{F}, \mathbf{0}\right)$. Note that Eq. 18 contains $i$ strictly positive elements more than Eq. 19 due to $i$ additional payments and limited recall. The profit difference $\Delta=\mathcal{S}\left(\boldsymbol{\theta}\left(\tau^{F}, \mathbf{0}\right)\right)-$ $\mathcal{S}\left(\boldsymbol{\theta}\left(\tau^{F}-\mathbf{1}, \boldsymbol{0}\right)\right)$ using Eq. 18 and 19 amounts to

$$
\Delta=S^{H}\left(\theta^{\tau^{F}-1}\right)+\sum_{t=\tau^{F}+1}^{2 \tau^{F}}\left[S^{D}\left(\theta^{t-1}\right)-S^{D}\left(\theta_{i}^{t-2}\right)\right] .
$$

Because of $\frac{d S^{H}}{d \gamma_{t-1}}>0$ and $\frac{d S^{D}}{d \gamma_{t-1}}>0$ for any history, payment in period $\tau^{F}$ under $\mathcal{S}\left(\boldsymbol{\theta}\left(\tau^{F}, \mathbf{0}\right)\right)$ provides for

$$
S^{D}\left(\theta^{t-1}\right)-S^{D}\left(\theta_{i}^{t-1}\right)>0, t=\tau^{F}+1, \ldots, 2 \tau^{F} .
$$

This proves $\mathcal{S}\left(\boldsymbol{\theta}\left(\tau^{F}, \mathbf{0}\right)\right)>\mathcal{S}\left(\boldsymbol{\theta}\left(\tau^{F}-\mathbf{1}, \mathbf{0}\right)\right)$. By iteration, it can be shown that $\mathcal{S}\left(\boldsymbol{\theta}\left(\tau^{F}-\mathbf{i}, \mathbf{0}\right)\right)>\mathcal{S}\left(\boldsymbol{\theta}\left(\tau^{F}-\mathbf{i}-\mathbf{1}, \mathbf{0}\right)\right), i=2, \ldots, \tau^{F}-1$. Thus, $\mathcal{S}\left(\boldsymbol{\theta}\left(\tau^{F}, \mathbf{0}\right)\right)>$ $\mathcal{S}\left(\boldsymbol{\theta}\left(\tau^{F}-\mathbf{i}, \mathbf{0}\right)\right)$ for all $i=1, \ldots, \tau^{F}-1$.

Next, we show that strategy $\boldsymbol{\theta}\left(\tau^{F}, \theta_{\tau^{F}+1}, \ldots, \theta_{T}\right)$, where the $\theta_{t}$ 's, $t=\tau^{F}+1$, $\ldots, T$, are optimally chosen, dominates all other possible strategies. Assume that strategy $\boldsymbol{\theta}\left(\tau^{F}-\mathbf{i}, \mathbf{0}\right)$ is changed by replacing a non-payment in period $t=\tilde{t}=$ $\tau^{F}-i+1, \ldots,\left(2 \tau^{F}-i\right)$ with a payment. Because $\frac{d^{2} S^{\prime \prime}}{d \gamma_{t-1}^{2}}>0$ and $\frac{d^{2} S^{D}}{d \gamma_{t-1}^{2}}>0-$ which only holds in case of limited recall so that the sample size or the denominator in the expected level of trust remains constant at $\tau^{F}$-marginal gains (losses) from payment (non-payment) are increasing in previous payments (non-payments). Hence, if a non-payment is replaced by a payment it has to be in period $\tilde{t}=$ $\tau^{F}-i+1$. Optimality of that replacement follows from the steps of the proof above implying $\mathcal{S}\left(\boldsymbol{\theta}\left(\tau^{F}-\mathbf{i}+\mathbf{1}, \mathbf{0}\right)\right)>\mathcal{S}\left(\boldsymbol{\theta}\left(\tau^{F}-\mathbf{i}, \mathbf{0}\right)\right)$. Again, by iteration the optimality of additional replacements in periods $\widetilde{t}=\tau^{F}-i+2, \ldots, \tau^{F}$ can be shown leading (again) to $\boldsymbol{\theta}\left(\tau^{F}, \mathbf{0}\right) \succ \boldsymbol{\theta}\left(\tau^{F}-\mathbf{i}, \mathbf{0}\right)$ for all $i=1, \ldots, \tau^{F}-1$. Obviously, $\boldsymbol{\theta}\left(\tau^{F}, \theta_{\tau^{F}+1}, \ldots, \theta_{T}\right) \succeq \boldsymbol{\theta}\left(\tau^{F}, \boldsymbol{0}\right)$ proving optimality of $\boldsymbol{\theta}\left(\tau^{F}, \theta_{\tau^{F}+1}, \ldots, \theta_{T}\right)$.

(b) Assume a sequence of $\tau^{F}$ payments has been selected leading to full trust. Now compare the following sequences

\footnotetext{
${ }^{29}$ Assuming $T>2 \tau^{F}$ under strategy $\boldsymbol{\theta}\left(\tau^{F}, \mathbf{0}\right)$ or $\boldsymbol{\theta}\left(\tau^{F}-\mathbf{i}, \mathbf{0}\right)$, respectively, trust is completely destroyed at the end of period $2 \tau^{F}$ or $\left(2 \tau^{F}-i\right)$, respectively, such that all future payoffs are zero.
} 


$$
\begin{aligned}
& \boldsymbol{\theta}_{d=1}=\left(\theta_{\tau^{F}+1}=0,1,1, \ldots, \theta_{2 \tau^{F}+2}=1\right) \\
& \boldsymbol{\theta}_{d=0}=\left(\theta_{\tau^{F}+1}=1,1,1, \ldots, \theta_{2 \tau^{F}+2}=1\right),
\end{aligned}
$$

starting in period $\tau^{F}+1$. Note that both sequences consist of $\left(\tau^{F}+1\right)$ elements to ensure that full trust is (re)established at the end of the sequences. The crucial step in the proof is that the trust level given $\theta_{d=1}$ remains constant after decision in period $\tau^{F}+1, \theta_{\tau^{F}+1}=0$, because when moving on from period $\left(\tau^{F}+1+i\right)$ to $\left(\tau^{F}+1+i+1\right), i \in\left\{1,2, \ldots, \tau^{F}\right\}$, the agent's limited recall capability "deletes" the payment in period $(i+1)$ from memory while "storing" the payment from period $\left(\tau^{F}+1+i\right)$. As such the single non-payment in period $\tau^{F}+1$ reduces the trust level from full trust 1 under $\boldsymbol{\theta}_{d=1}$ to $\frac{\tau^{F}-1}{\tau^{F}}$. Surpluses associated with Eqs. 21 and 22 then obtain as

$$
\begin{aligned}
\mathcal{S}\left(\boldsymbol{\theta}_{d=1}\right) & =\frac{3}{2}+\tau^{F} \cdot S^{H}\left(\frac{\tau^{F}-1}{\tau^{F}}\right) \\
& =\frac{3}{2}+\tau^{F} \cdot \frac{\tau^{F}-1}{2\left(\tau^{F}+1\right)} \\
\mathcal{S}\left(\boldsymbol{\theta}_{d=0}\right) & =\left(\tau^{F}+1\right) \cdot \frac{1}{2} .
\end{aligned}
$$

Some algebra shows that $\mathcal{S}\left(\boldsymbol{\theta}_{d=1}\right)>\mathcal{S}\left(\boldsymbol{\theta}_{d=0}\right)$ holds for any $\tau^{F}$.

(c) We know from part (a) and (b) that the principal's optimal strategy exhibits payment from period one to $\tau^{F}$ and at least one non-payment thereafter. From lemma 2 it is known that switching back and forth between one payment and one non-payment will never be optimal. Hence, the first sequence that is played consists of $\tau^{F}$ payments followed by $d \geq 1$ non-payments, $\theta^{R}\left(\tau^{F}, d\right)=\left(\theta_{1}=1\right.$, $\left.\theta_{2}=1, \ldots, \theta_{\tau^{F}}=1, \theta_{\tau^{F}+1}=0, \ldots, \theta_{\tau^{F}+d}=0\right)$. After $\theta^{R}\left(\tau^{F}, d\right)$ has been played once, induced trust is again less than one. Applying the same arguments as in (a) and (b) it is again optimal to re-induce full trust by paying the bonus $\tau^{F}$-times in a row and then harvesting it by $d$ non-payments in a row. Hence, at the optimum the representative sequence $\theta^{R}\left(\tau^{F}, d\right)$ will be repeated as long as possible given there are at least $\tau^{F}$-periods remaining to harvest trust after it has been raised to its maximum. The periods after the last repetition of $\theta^{R}\left(\tau^{F}, d\right)$ are subject to separate optimization.

As the results in (a), (b), and (c) are derived for $r=0$ they also hold for a sufficiently low interest rate.

Proof of Proposition 5 The idea of the proof is to transform strategies into profit annuities (the optimal strategy will have the highest profit annuity). Optimal strategies are characterized by their representative sequence. Effects of the ex ante distribution of trust are eliminated after initial play of $\tau^{F}$ payments (which have already been proven optimal). Subsequent repetitions of the representative sequence will then be played with recurring levels of trust solely determined by $\tau^{F}$ and $d$. The first decision and its associated profit which is not influenced by ex ante trust is the first non-payment after $\tau^{F}$ payments. Therefore we rearrange the representative sequence such that $d$ non-payments are followed by $\tau^{F}$ payments. With $\tau^{F}$ and $d$ given, the profit annuity $a\left(d, \tau^{F}\right)$ based on the decision sequence $\theta\left(d, \tau^{F}\right)$ obtains as 


$$
a\left(d, \tau^{F}\right)=A F\left(d, \tau^{F}\right) \cdot \pi_{0}\left(d, \tau^{F}\right),
$$

where $\pi_{0}=\left(\sum_{t=1}^{d} \frac{S_{1}^{D}\left(\gamma_{t-1}\right)}{(1+r)^{T}}+\sum_{t=d+1}^{\tau^{F}+d} \frac{S_{t}^{H}\left(\gamma_{t-1}\right)}{(1+r)^{T}}\right)$ denotes the present value resulting from playing the sequence once, and $A F\left(d, \tau^{F}\right)=\frac{(1+r)^{\left(\tau^{F}+d\right)} \cdot r}{(1+r)^{\left(r^{F}+d\right)}-1}$ is the annuity factor. (The dependence of $a\left(d, \tau^{F}\right)$ on $r$ is suppressed for notational brevity. For the same reason, both $d$ and $\tau^{F}$ are assumed to be continuous.)

Lemma 3 For a given $\tau^{F}$, the profit annuity $a(d, \tau)$ has a unique maximizer $d^{*}$.

Proof of Lemma 3 Note $\frac{\partial}{\partial d} A F\left(d, \tau^{F}\right)<0$. Furthermore, the first term $\sum_{t=1}^{d} \frac{S_{t}^{D}\left(\gamma_{t-1}\right)}{(1+r)^{\prime}}$ of $\pi_{0}\left(d, \tau^{F}\right)$ is increasing in $d$ : adding one non-payment adds $\frac{S_{d+1}^{D}\left(\gamma_{d}\right)}{(1+r)^{d+1}}$ to the sum while leaving previous summands unchanged; the second term $\sum_{t=d+1}^{\tau^{F}+d} \frac{S_{t}^{\prime \prime}\left(\gamma_{t-1}\right)}{(1+r)^{\prime}}$ is decreasing in $d$ : adding one non-payment decreases all $S_{t}^{H}\left(\gamma_{t-1}\right)$ because induced trust in all periods decreases. Hence either

(a) $\frac{\partial}{\partial d} \pi_{0}\left(d, \tau^{F}\right)<0 \forall d$, or

(b) $\frac{\partial}{\partial d} \pi_{0}\left(d, \tau^{F}\right)>0 \forall d$, or

(c) $\frac{\partial}{\partial d} \pi_{0}\left(d, \tau^{F}\right)<0 \forall d \in[1, \bar{d}]$ and $\frac{\partial}{\partial d} \pi_{0}\left(d, \tau^{F}\right)>0$ if $d \in\left(\bar{d}, \tau^{F}-1\right]$, or

(d) $\frac{\partial}{\partial d} \pi_{0}\left(d, \tau^{F}\right)>0 \forall d \in[1, \widetilde{d}]$ and $\frac{\partial}{\partial d} \pi_{0}\left(d, \tau^{F}\right)<0$ if $d \in\left(\widetilde{d}, \tau^{F}-1\right]$

must hold. The proof of proposition 4 shows $a\left(1, \tau^{F}\right)>a\left(0, \tau^{F}\right)$ for all $\tau^{F}$. Hence, either (b) or (d) holds. It follows, either (i) $\frac{\partial}{\partial d} a\left(d, \tau^{F}\right)>0$ for $\forall d \leq\left(\tau^{F}-1\right)$ holds, or (ii) $\frac{\partial}{\partial d} a\left(d, \tau^{F}\right)>0$ for $\forall d \in\left[1, d^{*}\right], d^{*} \leq \widetilde{d}$, and $\frac{\partial}{\partial d} a\left(d, \tau^{F}\right)<0$ if $d \in\left(d^{*}, \tau^{F}-1\right]$ must hold. Therefore $d^{*} \leq\left(\tau^{F}-1\right)$ is the unique maximizer of $a\left(d, \tau^{F}\right)$.

Now assume $d^{*}=\left(\tau^{F}-1\right)$ is the unique maximizer of $a\left(d, \tau^{F}\right)$. Then it is obvious that $d$ increases in $\tau^{F}$. Assume contrary to it $d^{*}<\left(\tau^{F}-1\right)$ to be optimal; hence $\left(d^{*}+1\right)$ is not optimal given $\tau^{F}$. The condition for optimality of $\left(d^{*}+1\right)$ using Eq. 23 obtains as

$$
\begin{aligned}
a\left(d^{*}+1, \tau^{F}\right) & >a\left(d^{*}, \tau^{F}\right) \\
\frac{A F\left(d^{*}+1, \tau^{F}\right)}{A F\left(d^{*}, \tau^{F}\right)} \cdot \pi_{0}\left(d^{*}+1, \tau^{F}\right) & >\pi_{0}\left(d^{*}, \tau^{F}\right)
\end{aligned}
$$

Observe, $\lim _{\tau^{F} \rightarrow \infty} \frac{A F\left(d^{*}+1, \tau^{*}\right)}{A F\left(d^{*}, \tau^{*}\right)}=1$. Therefore the left-hand side of (24) converges to $\lim _{\tau^{*} \rightarrow \infty} \pi_{0}\left(d^{*}+1, \tau^{F}\right)=\pi_{0}\left(d^{*}, \tau^{F}\right)+\frac{S_{d^{*}+1}^{D}\left(\gamma_{d^{*}}\right)-S_{d^{*}+1}^{H}\left(\gamma_{d^{*}}\right)}{(1+r)^{d^{*}+1}}$ and the relation in (24) will hold if $\tau^{F}$ increases sufficiently.

\section{References}

Aumann RJ, Maschler MB (1995) Repeated Games with Incomplete Information. MIT Press, Cambridge Baiman S, Rajan MV (1995) The informational advantages of discretionary bonus schemes. Account Rev 70(4):557-579

Baker G (1990) Pay-for-performance for middle managers: causes and consequences. J Appl Corp Fin $3: 50-61$ 
Baker G, Gibbons R, Murphy KJ (1994) Subjective performance measures in optimal incentive contracting. Q J Econ 109(4):1125-1156

Basu S, Waymire GB (2006) Recordkeeping and human evolution. Account Horiz 20(3):201-229

Basu S, Dickhaut J, Hecht G, Towry K, Waymire G (2007) Recordkeeping alters economics history by promoting reciprocity, Working paper

Binmore K, McCarthy J, Ponti G, Samuelson L (2002) A backward induction experiment. J Econ Theory 104(1):48-88

Boot AWA, Greenbaum SA, Thakor AV (1993) Reputation and discretion in financial contracting. Am Econ Rev 83(5):1165-1183

Boyle R, Bonacich P (1970) The development of trust and mistrust in mixed-motive games. Sociometry 33(2):123-139

Bull C (1987) The existence of self-enforcing implicit contracts. Q J Econ 102(1):147-160

Butler JK Jr (1983) Reciprocity of trust between professionals and their secretaries. Psychol Reports 53:411-416

Camerer C, Weigelt K (1988) Experimental tests of a sequential equilibrium reputation model. Econometrica 56(1):1-36

Campbell D, Lee C (1988) Self appraisal in performance evaluation: development versus evaluation. Acad Manage Rev 13:302-314

Campbell DJ, Campbell KM, Chia H-B (1998) Merit pay, performance appraisal, and individual motivation: an analysis and alternative. Hum Resour Manage 37(2):131-146

Casadesus-Masanell R (2004) Trust in agency. J Econ Manage Strategy 13(3):375-404

Casadesus-Masanell R, Spulber DF (2007) Agency revisited. Working Paper HBS and Northwestern University

Cripps MW, Mailath GJ, Samuelson L (2004) Imperfect monitoring and impermanent reputations. Econometrica 72(2):407-432

DeGroot MH (1970) Optimal statistical decisions. McGraw-Hill, New York

Folger R, Konovsky M (1989) Effects of procedural and distributive justice on reactions to pay raise decisions. Acad Manage J 32:115-130

Forges F (1992) Repeated games of incomplete information: non-zero-sum. In: Aumann RJ, Hart S (eds) Handbook of game theory with economic applications. Amsterdam, North Holland, pp 155-177

Friedman JA (1971) A non-cooperative equilibrium for supergames. Rev Econ Stud 38(1):1-12

Fudenberg D, Maskin E (1986) The folk theorem in repeated games with discounting or with incomplete information. Econometrica 54(3):533-554

Gibbs M, Merchant KA, Van der Stede WA, Vargus ME (2004) Determinants and effects of subjectivity in incentives. Account Rev 79(2):409-436

Green EJ, Porter RH (1984) Noncooperative collusion under imperfect price information. Econometrica 52(1):87-100

Gürtler O (2006) Implicit contracts: two different approaches. Working Paper University of Bonn

Hedge JW (2000) Exploring the concept of acceptability as a criterion for evaluating performance measures. Group Organ Manage 25(1):22-44

Hey JD, Knoll JA (2007) How far ahead do people plan? Econ Lett 96:8-13

Hopwood AG (1972) An empirical study of the role of accounting data in performance evaluation. J Account Res 10:156-182

Ittner CD, Larcker DF (2003) Coming up short on nonfinancial performance measurement. Harv Bus Rev 81(11):88-95

Ittner CD, Larcker DF, Meyer MW (2003) subjectivity and the weighting of performance measures: evidence from a balanced scorecard. Account Rev 78(3):725-758

John K, Nachman DC (1985) Risky debt, investment incentives, and reputation in a sequentia equilibrium. J Fin 40(3):863-878

Johnson EJ, Camerer C, Sen S, Rymon T (2002) Detecting failures of backward induction: monitoring information search in sequential bargaining. J Econ Theory 104(1):16-47

Jones GR, George JM (1998) The experience and evolution of trust: Implications for cooperation and teamwork. Acad Manage Rev 23(3):531-546

Jonker CM, Schalken JJP, Theeuwes J, Treur J (2004) Human experiments in trust dynamics. Lect Notes Comput Sci 2995:206-220

Kaplan RS, Norton DP (1996) Using the balanced scorecard as a strategic management system. Harv Bus Rev 74(Jan-Feb):75-87 
Kaplan RS, Norton DP (2001) The strategy-focused organization. Harvard Business School Press, Boston, MA

Kidder DL, Buchholtz AK (2002) Can excess bring success? CEO compensation and the psychological contract. Hum Resour Manage Rev 12(4):599-617

Kramer RM (1999) Trust and distrust in organizations: emerging perspectives, enduring questions. Ann Rev Psychol 50:569-598

Kreps DM, Wilson R (1982) Reputation and imperfect information. J Econ Theory 27(2):253-279

Kreps DM (1990) Corporate culture and economic theory. In: Alt JE, Shepsle KA (eds) Perspectives on positive political economy. Cambridge University Press, Cambridge, pp 90-143

Levin J (2003) Relational incentive contracts. Am Econ Rev 93(3):835-857

Lewicki R, Bunker BB (1995) Developing and maintaining trust in work relationships. In: Kramer RM, Tyler TR (eds) Trust in organizations: frontiers of theory and research. SAGE Publications, Thousand Oaks, pp 114-139

Luhmann N (1979) Trust and power. Wiley, New York

MacLeod B (2003) Optimal contracting with subjective evaluation. The Am Econ Rev 93(1):216-240

Mailath GJ, Morris S (2002) Repeated games with almost-public monitoring. J Econ Theory 102:189202

Mailath GJ, Morris S (2006) Coordination failure in repeated games with almost-public monitoring. Theor Econ 1:311-340

Mailath GJ, Samuelson L (2001) Who wants a good reputation? Rev Econ Stud 68(2):415-441

Mailath GJ, Samuelson L (2006) Repeated games and reputations: long-run relationships. Oxford University Press, Oxford

March JG (1994) A primer on decision making: how decisions happen. The Free Press, New York

McKnight DH, Cummings LL, Chervany NL (1998) Initial trust formation in new organizational relationships. Acad Manage Rev 23(3):473-490

Milkovich GT, Newman JM (2002) Compensation, 7th edn. McGraw-Hill, Irwin

Mitusch K (2006) Non-commitment in performance evaluation and the problem of information distortions. J Econ Behav Organ 60(4):507-525

Murphy KJ, Oyer P (2003) Discretion in executive incentive contracts: theory and evidence. Working paper

Nooteboom B (2006) Forms, sources and processes of trust. In: Bachmann R, Zaherr A (eds) Handbook of trust research. Edward Elgar, Cheltenham, pp 247-263

Phelan C (2006) Public trust and government betrayal. J Econ Theory 130:27-43

Prendergast C (1999) The Provisions of Incentives in Firms. J Econ Lit 37:7-63

Rajan MV, Reichelstein S (2009) Objective versus subjective indicators of managerial performance. Account Rev 84:209-237

Robinson SL, Rousseau DM (1994) Violating the psychological contract: not the exception but the norm J Organ Behav 15(3):245-259

Robinson SL (1996) Trust and breach of the psychological contract. Ad Sci Q 41(4):574-599

Rosen S (1992) Contracts and the market for executives. In: Wessin L, Wijkander H (eds) Contract economics. Blackwell, Oxford, pp 181-211

Rousseau DM (1990) New hire perceptions of their own and their employer's obligations: a study of psychological contracts. J Organ Behav 11(5):389-400

Wicks AC, Berman SL, Jones TM (1999) The structure of optimal trust: moral and strategic implications. Acad Manage Rev 24(1):99-116

Wiseman T (2008) Reputation and impermanent types. Games Econ Behav 62:190-210

Wixted JT (2004) The psychology and neuroscience of forgetting. Ann Rev Psychol 55:235-269

Worchel P (1979) Trust and distrust. In: Austin WG, Worchel S (eds) The social psychology of intergroup relations. Brooks/Cole Publishing, Monterey CA, pp 174-187 